\title{
COMPARAÇÃO ENTRE UM POVOAMENTO DE EUCALIPTO SOB DIFERENTES PRÁTICAS DE MANEJO E VEGETAÇÃO NATURAL DE CERRADÃO, ATRAVÉS DA RESPIRAÇÃO, INFILTRAÇÃO DE ÁGUA E MESOFAUNA DO SOLO
}

\section{ANA CLÁUDIA SILVA DE LIRA}

Engenheira Agrônoma

Orientador: Prof. Dr. FÁBIO POGGIANI

Dissertação apresentada à Escola Superior de Agricultura "Luiz de Queiroz", Universidade de São Paulo, para a obtenção do título de Mestre em Ciências, Área de concentração: Ciências Florestais.

PIRACICABA

Estado de São Paulo - Brasil

Janeiro - 1999 


\section{ERRATA}

Onde se lê madereiros, p. 2, parágrafo 2, lê-se madeireiros.

Onde se lê organismos, p. 7, parágrafo 1, lê-se animais.

Onde se lê Fitkau e Klinge, p.9, parágrafo 3, lê-se Fitkau \& Klinge.

Onde se lê no que diz respeito à mobilização de nutrientes através de enzimas do melhoramento da estrutura $e$ através da ativação da microvida, p. 9 e 10, parágrafo 4, lê-se no que diz respeito à mobilização de nutrientes, através de enzimas; e o melhoramento da estrutura, através da ativação da microvida.

Onde se lê ente, p. 14, parágrafo 1, lê-se entre.

Onde se lê que no TMC, p. 31, parágrafo 1, lê-se que o TMC.

Onde se lê Santos e Grisi, p. 36, parágrafo 2, lê-se Santos \& Grisi.

Onde se lê Ainda na Tabela 7, verifica-se que predominaram os ácaros e que não houve presença de colêmbolos. p. 47, parágrafo 1, lê-se Ainda na Tabela 7 , verifica-se que predominaram os ácaros e que não houve presença de colêmbolos no tipo de manejo $C$.

Onde se lê 2106,06535, p. 53, Anexo B, lê-se 210,606535. 
Dados Internacionais de catalogação na Publicação (CIP) DIVISÃo DE BIBLIOTECA E DOCUMENTAÇÃo - Campus "Luiz de Queiroz"/USP

Lira, Ana Cláudia Silva de

Comparação entre povoamento de eucalipto sob diferentes práticas de manejo e vegetação natural de cerradão, através da respiração, infiltração de água e mesofauna do solo / Ana Cláudia Silva de Lira. - Piracicaba, 1999

p.

Dissertação (mestrado) - - Escola Superior de Agricultura Luiz de Queiroz, 1998. Bibliografia.

1. Biologia do solo 2. Cerrado 3. Eucalipto 4. Fauna do solo 5. Manejo do solo 6. Propriedade fisico-química do solo 7 . Vegetação nativa I. Título

CDD 634.9734 
ii

O papel das flores, na CRIAÇÃO

${ }^{\text {"Que a flor traga beleza. }}$

Que a beleza traga inspiração.

Que a inspiração seja luz.

Que a luz germine a semente.

Que da semente brote o amor.

Que o amor seja perfeito.

Que o amor perfeito se transforme em flor.

Para que a flor seja beleza

e assim se fez a Floresta"

(George Matsas) 


\begin{abstract}
À toda a minha Família, principalmente ao meu pai, que com o corpo cansado e um olhar para o infinito, me mostrou a importância da natureza.
\end{abstract}

\title{
Ofereço
}

Aos meus pequeninos: Natan, Bruno, Carol, Tatá, July, Godão, Mila e Maristela. Para que eles, seus filhos e seus netos ainda possam usufruir da beleza e riqueza das Florestas. 


\section{AGRADECIMENTOS}

A Deus, por sempre estar presente, mostrando e iluminando o meu caminho;

Ao Prof. Dr. Fábio Poggiani e Prof. Dr. José Leonardo Gonçalves pela orientação durante o desenvolvimento deste trabalho;

Ao Professor do IAC (Instituto Agronômico de Campinas), Dr. Sidney Vieira pelas instruçōes sobre a metodologia utilizada para medir a velocidade de infiltração de água no solo;

À Professora Maria Izalina Alves, pela valiosa orientação em parte das análises estatísticas de todas as variáveis;

Ao aluno Aníbal Ramadan pela ajuda na identificação da mesofauna do solo, e ainda pela orientação e sugestões de literatura;

À Coordenação de Aperfeiçoamento de Pessoal de nível Superior (CAPES) pela concessão de bolsa de estudos para o mestrado;

Aos funcionários da companhia SUZANO PAPEL E CELULOSE, que, com boa vontade, sempre ajudaram tanto no serviço de campo como de laboratório; em especial: Góes, Ederaldo, Leonardo, S. Nilson, S. Jademir, S. José Conterno e Marlene.

Aos funcionários e estagiários da ESALQ, em especial: José Amarildo, Ivan Moura, José Martins, Francismara Duarte, Elza Ferraz, Denise Mescolotti e Gertrudes, por sempre estarem prontos a ajudar no que fosse preciso;

Aos colegas de pós-graduação: Carla Câmara, Kátia Geórgia, Kathya Mendes, Simone Vieira, Edson Vidal, Luciana Kolm e Viviana Oki, pela união nos estudos e incentivo em todos os momentos; 
Aos Professores da Faculdade de Ciências Agrárias do Pará (FCAP): Carlos Costa, Marco Aurélio, Geraldo Coqueiro e Pedro Gazel pelo respeito e confiança desde a graduação;

Aos meus amigos do curso de Agronomia, em especial: Antônio Selso, Antônio Vieira, Ewerton Cunha, Izabel Cristina, Luciana Barros, Marcos André, Margarida Sabino, Vânia Silva e Wagner Nazareno;

Às Amigas Cristina Lacerda (Cris), Rosa Santos (My Love), Zilda de Fátima (Globeleuza), Lucieta Martorano (Lutynha), Betânia Lúcia (BB), Michelle Costa (Micha), Mônica Brainer (Lôra Aguada), Jeane Portela e Sylvia Elaine pela amizade, incentivo e sorrisos;

A todos os companheiros da Vila da pós-graduação da ESALQ/USP, em especial, ao Fábio Prudêncio, Marcelo Alves, Paulo Andrade, Francisco Casimiro, Vanderlei Rofer, Elton Lúcio, Quelmo José, Norberto Cornejo (Beto), Walter Robles, Rafael Costa (Rafaelzinho), Jailson Fagundes (Rato), Antônio Sampaio (Toinho) e Evandro Zanini;

Ao meu primo querido: Edevaldo Azevedo e meus amigos de sempre Cleniva Freitas, Rosely Brito, Daniel Miranda, João Santana, Jhon e Nazaré Menezes;

A todos aqueles que de alguma maneira colaboraram para a realização desta dissertação. 


\section{SUMÁRIO}

LISTA DE TABELAS

Página

LISTA DE FIGURAS

viii

LISTA DE ANEXOS

ix

RESUMO

$x$

xi

SUMMARY

xiii

1 INTRODUÇÃO

1

2 REVISÃO DE LITERATURA

3

2.1 Respiração edáfica

2.2 Velocidade de infiltração de água no solo

2.3 Mesofauna do solo

2.4 Ecossistema de cerrado

2.5 As plantações florestais de eucalipto

3 MATERIAL E MÉTODOS

3.1 Área de estudo

3.1.1 Condições climáticas

3.1.2 Condiçōes edáficas

3.1.3 Condições florísticas 
3.3 Delineamento experimental 20

3.4 Liberação de $\mathrm{CO}_{2} \quad 22$

3.5 Velocidade de infiltração de água no solo 24

$\begin{array}{ll}\text { 3.6 Mesofauna do solo } & 25\end{array}$

3.7 Dados meteorológicos, temperatura e umidade do solo e fertilidade 26

$\begin{array}{ll}3.8 \text { Análise de dados } & 27\end{array}$

4 RESULTADOS E DISCUSSĀO 28

4.1 Temperatura e umidade do solo 28

4.2 A influência dos tipos de manejo na fertilidade do solo 31

4.3 Respirometria do solo $\quad 35$

4.3.1 Comparação entre os diferentes tipos de manejo 35

4.3.2 Comparação entre o povoamento de eucalipto e a vegetação 38 natural (cerradão)

4.4. Velocidade de infiltração de água no solo 40

4.4.1 Comparação entre os diferentes tipos de manejo 40

4.4.2 Comparação entre o povoamento de eucalipto e a vegetação natural (cerradão)

4.5 Mesofauna do solo $\quad 44$

4.5.1 Comparação entre os diferentes tipos de manejo 45

4.5.2 Comparação entre o povoamento de eucalipto e vegetação 47 natural (cerradão)

5 CONCLUSÕES E CONSIDERAÇÕES FINAIS

$\begin{array}{ll}\text { ANEXOS } & 52\end{array}$

REFERÊNCIAS BIBLIOGRÁFICAS $\quad 56$ 


\section{LISTA DE TABELAS}

Página

Tabela 1 İndice de chuva e médias das temperaturas máximas e mínimas do ar e do solo nas áreas estudadas

Tabela 2 Umidade do solo a $5 \mathrm{~cm}$ nos diferentes tipos de manejo estudados no povoamento de eucalipto e na vegetação natural (cerradão)

Tabela 3 Características químicas do solo sob povoamento de eucalipto (junho/96)

Tabela 4 Características químicas do solo sob povoamento de eucalipto (setembro/97)

Tabela 5 Valores médios da velocidade de infiltração de água no solo sob povoamento de eucalipto e vegetação natural (cerradão)

Tabela 6 Número de indivíduos pertencentes aos diferentes grupos faunísticos presentes nos ambientes estudados

Tabela 7 Valores observados de grupos de animais que representa a mesofauna edáfica de um solo sob povoamento de Eucalyptus grandis submetido a diferentes tipos de manejo

Tabela 8 Valores observados de grupos de animais que representam a mesofauna edáfica de um solo sob povoamento de eucalipto (TMA) e vegetação natural (cerradão) 


\section{LISTA DE FIGURAS}

Página

Figura 1 Balanço hídrico, segundo Thornthwaite \& Mather (1995), considerando o período de janeiro a dezembro de 1997 e 125 $\mathrm{mm}$ de capacidade de armazenamento de água do solo

Figura 2 Croqui da área experimental, apresentando a distribuição dos tipos de manejo

Figura 3 Desenho esquemático do método utilizado para medir a respirometria no campo

Figura 4 Desenho esquemático do permeâmetro de campo

Figura 5 Esquema do extrator da mesofauna do solo

Figura 6 Médias geral de $\mathrm{CO}_{2}$ liberado nos diferentes tipos de manejo do povoamento de eucalipto

Figura 7 Médias geral de $\mathrm{CO}_{2}$ liberado do solo considerando todos os tratamentos do povoamento de eucalipto ao longo do tempo

Figura 8 Médias mensais de emissão de $\mathrm{CO}_{2}$ no tipo de manejo A (TMA) e na vegetação natural (VN)

Figura 9 Velocidade de infiltração básica medida em duas profundidades, durante o mês de setembro de 1997, em solo sob povoamento de Eucalyptus grandis submetido a diferentes tipos de manejo 


\section{LISTA DE ANEXOS}

Página

Anexo A Análise da variância e teste $\mathrm{F}$ para $\circ \mathrm{CO}_{2}$ liberado do solo sob eucalipto (dados transformados $\Rightarrow x=1 / y$ )

Anexo B Teste $\mathrm{T}$ para as médias originais de $\mathrm{CO}_{2}$ entre vegetação natural (cerradão) e o povoamento de eucaliptos

53

Anexo C Análise de variância e teste $F$ para a velocidade de infiltração básica no povoamento de eucalipto (dados transformados $\Longrightarrow$ $x=\ln (Y))$

Anexo D Teste $\chi^{2}$ para a mesofauna edáfica do povoamento de eucaliptos sob diferentes práticas de manejo

Anexo E Teste $\chi^{2}$ para a mesofauna edáfica do povoamento de eucaliptos (TMA) e vegetação natural (cerradão) 


\title{
COMPARAÇÃO ENTRE UM POVOAMENTO DE EUCALIPTO SOB DIFERENTES PRÁTICAS DE MANEJO E VEGETAÇÃO NATURAL DE CERRADÃO, ATRAVÉS DA RESPIRAÇÃO, INFILTRAÇÃO DE ÁGUA E MESOFAUNA DO SOLO
}

\author{
Autora: ANA CLÁUDIA SILVA DE LIRA \\ Orientador: Prof. Dr. FÁBIO POGGIANI
}

RESUMO

A ciclagem de nutrientes é um processo de grande importância para a sustentabilidade de ecossistemas. Este processo depende da decomposição dos resíduos orgânicos, que é altamente influenciada por alguns fatores, como: a atividade biológica e a permeabilidade do solo. Com o objetivo de avaliar o impacto causado sobre um povoamento de eucalipto submetido à diferentes práticas de manejo, comparando com um cerradão (vegetação natural), foram estudados os seguintes indicadores ecológicos: a emissão de $\mathrm{CO}_{2}$, a velocidade de infiltração de água no solo e ainda procedeu-se à identificação e quantificação da mesofauna edáfica. $\mathrm{O}$ estudo foi conduzido na Fazenda Entre Rios - Cia Suzano Papel e Celulose, em Itatinga - SP, onde parte do povoamento foi cortado e parte deixado intacto. $O$ corte foi realizado no mês de julho/1995, a instalação do experimento (práticas de manejo) em agosto/1995 e o replantio das mudas de Eucalyptus grandis setembro/1995. As práticas de manejo no povoamento foram as seguintes: 1) manutenção do povoamento de eucalipto intacto (TMA), 2) manutenção dos restos culturais e serapilheira na superfície do solo (TMC), 3) remoção dos restos culturais e serapilheira (TME), 4) incorporação dos restos culturais e serapilheira com gradagem (TMF) e 5) queima dos restos culturais (TMG). A liberação de $\mathrm{CO}_{2}$ foi 
medida mensalmente, no período de junho/97 a fevereiro/98, empregando-se o método de absorção sob campânula em condições de campo. Verificou-se que houve diferença significativa entre os tipos de manejo $(F=3,398, p=0,04)$ e entre as épocas de avaliação ( $F=41,764, p<0,001)$.No entanto, não houve efeito significativo da interação entre o tipo de manejo e o tempo. O TMG foi o sistema que apresentou a maior média de $\mathrm{CO}_{2}$ liberado, e o TMA, a menor. Para todos os tipos de manejo, a maior média de liberação de $\mathrm{CO}_{2}$ ocorreu no período de novembro/97 a fevereiro/98, correspondendo ao final da primavera e durante todo o verão. A média da liberação de $\mathrm{CO}_{2}$ no cerradão foi maior do que no povoamento de eucalipto durante todos os meses, indicando haver uma maior atividade biológica neste ecossistema. A velocidade de infiltração de água no solo (VIB) foi medida no mês de setembro/97 em duas profundidades (6 e 20 $\mathrm{cm}$ ), utilizando-se um permeâmetro de campo. Houve efeito significativo apenas entre as profundidades $(F=16,696, p<0,001)$, sendo maior na profundidade de $20 \mathrm{~cm}$. Observou-se também maiores valores de velocidade de infiltração básica para os tipos de manejo $A$ e E. Comparando o cerradão com 0 povoamento de eucalipto sob o TMA, observou-se que em ambas as profundidades, o primeiro ecossistema apresentou maiores valores de velocidade de infiltração básica. A coleta do solo para a extração da mesofauna foi realizada no mês de agosto/97, e para a sua análise, utilizou-se o método de Berlese-Tullgren. Foi constatada a existência de 8 grupos faunísticos, tanto no povoamento de eucalipto como no cerradão. No povoamento de eucalipto, os sistemas TMC e TMA apresentaram a maior população de mesofauna. Isto pode ser atribuído à presença de resíduos vegetais na superfície do solo destes tipos de manejo. Na vegetação natural (cerradão), a população de mesofauna foi muito maior do que aquela encontrada no TMA do povoamento de eucalipto, evidenciando que neste ecossistema, há uma maior complexidade ecológica. Com base nos resultados obtidos, pode-se concluir que os parâmetros estudados poderão ser utilizados como indicadores ecológicos para acompanhar a evolução das condições edáficas em povoamentos florestais. 


\title{
COMPARISON BETWEEN AN EUCALYPTUS PLANTATION UNDER DIFFERENT MANAGEMENT PRACTICES AND A NATURAL VEGETATION (CERRADÃO) THROUHGOUT RESPIRATION, WATER INFILTRATION AND SOIL MESOFAUNA
}

\author{
AUTHOR: ANA CLÁUDIA SILVA DE LIRA \\ ADVISER: Prof. Dr. FÁBIO POGGIANI
}

\section{SUMMARY}

Nutrient cycling is an important process for ecosystem maintenance. This process depends on organical residues decomposition and it is highly influenced by some factors like biological activity and soil permeability. The impact caused by different management procedures on an eucalyptus plantation when compared to natural vegetation (cerradão) was studied according the following ecological parameters: $\mathrm{CO}_{2}$ emission, soil water infiltration speed and edaphical mesofauna. All the procedures were carried out at Fazenda Entre Rios- Cia. Suzano de Papel e Celulose, in Itatinga, SP, Brazil, where part of the eucalyptus plantation was fell off and part remained untouched. The felling of the plantation took place in July, 1995, and the experiment (managements) was installed in August, 1995. Eucalyptus grandis seedlings were replanted in September, 1995. Managements practices for the plantation were as follow: 1) the preservation of an untouched plantation (TMA); 2) the keeping of cultural remains and litter on soil surface (TMC); 3 ) the removing of cultural remains and litter (TME); 4) the incorporation of cultural remains and litter by griding (TMF); 5) the burning of cultural remains (TMG). $\mathrm{CO}_{2}$ liberation was monthly measured from June, 97 , to February, 98 , by the method of absortion under campanula in field conditions. It was shown a 
significative difference between management types $(F=3.398, p=0.04)$ and between evaluation periods $(F=41.764, p<0.001)$. On the other hand, no significative effect on the interaction between management type and time was detected. TMG system showed the highest average of $\mathrm{CO}_{2}$ liberation and TMA the smallest one. Increased rates of $\mathrm{CO}_{2}$ liberation were detected from November, 97, to February, 98, correspondig to the end of springtime to the begining of summer. The average of $\mathrm{CO}_{2}$ liberation was higher during the whole period and it indicates an increased biological activity for this ecosystem. Water infiltration in the soil (VIB) had it speed measured along September, 97, in two different depth levels ( 6 and $20 \mathrm{~cm}$ ), using a field permeameter. A significative effect was shown between them ( $F=16,696 ; p<0.001)$, and it was higher at 20 $\mathrm{cm}$. Increased values for basic infiltration speed were observed for $A$ and $E$ management types as well. For both depth levels the natural vegetation ecosystem showed higher values for basic infiltration speed. Soil was collected in August, 97, for mesofauna extraction and analyses were performed according to Berlese-Tullgren. Eight fauna groups were identified either for natural vegetation (cerradão) or eucalytus plantation and for this one TMC and TMA systems were found to have a higher mesofauna plantation and it might be due to vegetal remainings on soil surface. The natural vegetation (cerradão) mesofauna plantation was much higher than the one found at TMA euclyputs plantation, pointing out a larger ecological complexity for this ecosystem. According to these results one might conclude that these parameters can be used as ecological indicatives to follow the evolution of edaphical conditions in forest plantations. 


\section{INTRODUÇÃO}

Atualmente, há um grande interesse em se conhecer o funcionamento dos ecossistemas florestais, sobretudo no que se refere à sua produtividade. Sob o ponto de vista ecológico, năo só a produtividade é importante, mas também o equilíbrio a longo prazo, que depende, em grande parte, da ciclagem de nutrientes. Esta depende da adição e decomposição dos restos vegetais e animais, sob a atuação de organismos presentes no solo. Este processo acontece tanto em ecossistemas naturais como nos artificiais; sendo contudo menos intenso nestes últimos. 0 principal fator que contribui para isso é a maior complexidade de formas de vida da cadeia alimentar de ecossistemas naturais.

Segundo Cardoso (1992), o solo é um habitat microbiano por excelência, local de vida de inúmeras populaçóes de vários tipos de microrganismos. O mesmo autor ressalta ainda, que este habitat se constitui de inúmeros micrositios, caracterizados não apenas pelas condiçőes edafoclimáticas, mas ainda por fatores peculiares, como a presença de matéría orgânica, raízes de vegetais, microporos saturados por água, maior ou menor facilidade de trocas gasosas, dentre outros. Para Primavesi (1990), os seres vivos do solo fazem parte dele, modificando-o e influenciando-se. Sendo assim, - solo funciona como um corpo vivo, possuindo um metabolismo, uma temperatura e uma respiração

Larvas de insetos, besouros, minhocas e formigas constróem pequenos canais que permitem a circulação de ar e água, bem como a penetração das raízes das plantas no solo. Além disso, esses organismos 
trituram os restos vegetais, auxiliando em sua decomposição, que resultará na liberação de nutrientes vegetais e na formação do húmus que melhora a estrutura do solo. Os organismos produzem substâncias de crescimento que atuam na defesa contra pragas e doenças; possuem a função de "colar" os agregados do solo, formados pelos minerais; produzem ácidos que "dissolvem" os nutrientes que fazem parte dos minerais presentes no solo, como é o caso do fósforo e potássio, tornando-os assimiláveis pelas plantas.

Além dos organismos do solo, outros fatores influenciam seus processos físicos, químicos e biológicos; dentre estes podem ser citados: a temperatura, a umidade, a aeração e reação do solo, a fisionomia da vegetação e as práticas de manejo, dentre outros.

A retirada de uma vegetaçāo natural para implantação de monocultivos, possivelmente acarretará modificações na composição química, física e biológica do solo, principalmente, quando se tratar de plantações situadas em solos de baixa fertilidade, destinada à extração de produtos madereiros. Contudo, tais modificações podem ser amenizadas, com a utilizaçäo de práticas adequadas de manejo do solo. Gonçalves (1995) ressalta que nos últimos dez anos, vem sendo difundido no setor florestal, o sistema de cultivo mínimo, que é uma prática baseada no preparo do solo restrito às linhas ou covas de plantio, mantendo-se os restos culturais sobre o terreno.

Espera-se que em solo sob povoamento de eucalipto, bem como em solo sob vegetação natural (cerradâo), existam características peculiares. 0 objetivo desta pesquisa foi avaliar o impacto causado sobre um povoamento de eucalipto sobmetido à diferentes práticas de manejo, comparando com um cerradão (vegetação natural), através dos seguintes indicadores ecológicos:

1) taxa de dióxido de carbono liberado pelo solo;

2) velocidade de infiltração de água no solo (VIB); e

3) população da mesofauna edáfica. 


\section{REVISÃO DE LITERATURA}

\subsection{Respiração edáfica}

A respiração do solo é o desprendimento do $\mathrm{CO}_{2}$ através da superfície deste, e segundo Schlenter \& Cleve (1985), este processo surge de, pelo menos, três fontes metabólicas: a respiração microbiana, respiração das raízes e respiração dos organismos. Além disso, podem ser incluídas ainda, algumas fontes não metabólicas como a oxidação química dos minerais do solo.

Poggiani et al. (1977), trabalhando com a respiração edáfica em plantações de coniferas (Pinus) e folhosas exóticas (Liquidambar) em área de cerrado, verificaram que as condiçōes climáticas possuem uma acentuada influência sobre a evolução de $\mathrm{CO}_{2}$ do solo. Por outro lado, observaram pequena diferença entre as médias gerais de liberação de $\mathrm{CO}_{2}$ nos tratamentos, sendo a maior verificada no talhão de Liquidambar, em seguida o talhão de consorciação de Liquidambar e Pinus e a menor no talhão de Pinus.

Martins \& Matthes (1978), ao medirem a respiração edáfica em Floresta Arenicola, Campinarana e Campina em Manaus (AM), obtiveram médias $\left(\mathrm{mg} \mathrm{CO}_{2} \mathrm{~m}^{-2} \mathrm{~h}^{-1}\right)$ de 60,18; 52,85 e 44,99 respectivamente, sendo estes valores esperados, pois as biomassas dos três tipos fisionômicos de vegetação se apresentavam, aparentemente, diferentes.

Santos \& Grisi (1981) ao analisarem o efeito do desmatamento na atividade dos microrganismos de um solo de terra firme na Amazônia, ressaltaram que a queima parece exercer, pelo menos, nos primeiros anos de desenvolvimento da vegetação secundária, uma ação benéfica sobre a 
atividade dos microrganismos, aumentando a liberação de $\mathrm{CO}_{2}$, devendo este fato, provavelmente, às mudanças nas propriedades edáficas, ocorridas após a ação do fogo sobre a fitomassa.

Poggiani et al. (1983) ao estudarem os efeitos do fogo na brotação e crescimento de Eucalyptus grandis logo após o corte raso e as alterações nas propriedades do solo, verificaram que no invemo a respiração edáfica diária apresentou valores baixos em função das menores temperaturas, enquanto que no verăo, devido ao aumento da temperatura e a um melhor suprimento de água no solo, houve uma atividade microbiana mais intensa e, consequentemente, um aumento na liberação do $\mathrm{CO}_{2}$. No entanto, foi verificado que os valores diários não se apresentavam constantes em conseqüência das variações de temperatura. Os mesmos autores evidenciaram uma diminuição da liberação do $\mathrm{CO}_{2}$ nas áreas queimadas, no período do verão, devido, possivelmente, a uma diminuição da flora bacteriana, resultante da própria destruição da matéria orgânica da parte superficial do solo.

Weber (1990) ao determinar a respiração do solo depois do corte e queima em ecossistemas imaturos, usando a "soda lime", observou que os níveis de liberação de dióxido de carbono variaram sazonalmente de uma alta de verão e uma baixa na primavera e outono. Foi observado também, que em áreas cortadas e queimadas houve um declínio temporário em taxas de respiração do solo.

Toland \& Zak (1994), ao investigarem a influência da respiração do solo em padrões sazonais sobre a produtividade florestal em dois diferentes ecossistemas, verificaram que a respiração de raiz diminuía enquanto que a respiração microbiana aumentava, em respostas às temperaturas mais quentes do solo e à maior disponibilidade de carbono neste. A taxa máxima de emissão de $\mathrm{CO}_{2}$ foi verificada, durante o meio e o final do verão.

Pesquisas comprovam que a liberação de $\mathrm{CO}_{2}$ é limitada pelo "status" nutricional do solo, sendo o nitrogênio, o nutriente que mais limita o processo. Sampaio \& Salcedo (1982), verificaram que a liberação de $\mathrm{CO}_{2}$ foi 
menor em tratamentos com mais nitrogênio, mas ela pode ou não ter sido compensada por maior formação de biomassa microbiana. Munevar \& Wollum (1977) também encontraram decréscimo na liberação de $\mathrm{CO}_{2}$ com a adição de nitrogênio $e$ inferiram que este fato se deu a uma maior incorporação de carbono na biomassa microbiana.

Fatores que limitam a decomposição de serapilheira de eucalipto foram estudados por Della Bruna et al. (1991). Os autores observaram que a atividade da microbiota foi maior sob mata nativa do que sob eucalipto, e que a adição de $\mathrm{P}$ e $\mathrm{N}$ incrementou a quantidade de $\mathrm{CO}_{2}$ desprendido.

Graça (1997), estimando o estoque de carbono contido na biomassa florestal da Amazônia e seu potencial em liberar carbono para a atmosfera através da queima, observou que a matéria orgânica do solo foi pouco afetada e o teor de carbono teve um aumento não significativo, imediatamente após o corte e a queima, sendo que depois de um ano, a tendência foi de decréscimo.

\subsection{Velocidade da infiltração da água no solo}

Denomina-se infiltração ao processo pelo qual a água entra no solo, que perdura enquanto houver fornecimento da mesma. Este processo é de grande importância prática, pois sua velocidade muitas vezes determina o deflúvio superficial ou enxurrada, responsável pela erosão durante precipitações pluviais. A infiltração determina o balanço de água na zona das raizes e, por essa razão, o conhecimento deste processo e suas relações com as propriedades do solo é de fundamental importância para um manejo eficiente do solo e da água (Reichardt, 1996), bem como para a produção vegetal, pois esse fator, muitas vezes, determina se haverá ou não suficiente umidade para as plantas (Bertoni, 1959). 
Para Musgrave \& Holtan (1964), a infiltração pode ser considerada como uma seqüência de três fases: a) a entrada de água pela superficie, b) sua transmissão no perfil e c) a perda da capacidade de armazenamento do solo. Estas fases, interagindo com as características do solo e da água formam os fatores que podem afetar o processo de infiltração.

Baver et al. (1973) citam que a quantidade de água que percola através de um perfil de solo é determinada pelo horizonte menos permeável. Quando este horizonte se encontra no subsolo, a permeabilidade de todo perfil dependerá da velocidade do movimento da água nessa região. Assim, o máximo de capacidade de infiltração depende da permeabilidade dos horizontes acima do subsolo. Uma vez saturados, a velocidade de percolação do subsolo regulará a absorção posterior de água e então alcança a capacidade de infiltração mínima. Se o horizonte menos permeável do solo está na superfície, a velocidade do movimento da água através do perfil será limitada pela velocidade de infiltração na superfície.

De acordo com Skaggs \& Khaeel (1988), quando a precipitação pluvial tem menor intensidade que a capacidade de infiltração do solo, toda a água penetra no solo, sendo a infiltração muito mais limitada pela precipitação que pelas características do solo propriamente ditas. Já, quando a precipitação é maior que a capacidade de infiltração do solo, esta é limitada pelas características do perfil e haverá água disponível para a armazenagem sobre o solo ou para o escoamento superficial.

A matéria orgânica melhora a drenagem do solo, isto é, a capacidade que este possui, de permitir que a água se mova com certa velocidade entre os agregados e as partículas, de maneira a não ocasionar prolongados encharcamentos quando forem previamente saturados (Kiehl, 1985). Bertoni \& Pestana (1964) e Foglino (1965), afirmam que a matéria orgânica é responsável pela formação de terra grumosa, e esta por sua vez, permite a pronta infiltração da água e penetração das raízes dos vegetais. 
O uso e o manejo inadequado do solo pode reduzir a infiltração da água neste, através de: a) compactação provocada por excessivo trânsito de veículos e máquinas, ou excesso de pisoteio de organismos; b) degradação da estrutura do solo por métodos impróprios de cultivo e preparo; c) retirada indiscriminada da cobertura vegetal para usos agrícolas, urbanização $e$ mineração sem observância de legislação florestal, dentre outros (BRASIL, 1983).

As propriedades do solo têm uma influência marcante sobre a velocidade de infiltração. Durante os estágios iniciais, a estrutura do solo ou a distribuição dos tamanhos dos poros, tem uma importância considerável. Nas condiçōes de saturação e, principalmente, para profundidades crescentes, o gradiente hidráulico aproxima-se da unidade e a condutividade hidráulica passa a controlar o fluxo. Sendo que a água se move no solo através do espaço poroso, uma variação na textura ou na estrutura provoca uma variação na característica do movimento da água (Aguiar, 1997).

Os sistemas de preparo do solo afetam os processos de infiltração, pelas modificaçōes introduzidas na rugosidade superficial, na porosidade e na cobertura do solo. Afetam também a retenção, armazenamento e evaporação da água (Hillel, 1980).

Hillel (1970) ressalta que no início do processo de infiltração, quando o solo ainda está seco, esta ocorre sob a ação da gravidade e do gradiente de potencial de água no solo; daí a velocidade de infiltração vai diminuindo com o aumento do teor de umidade, sendo que, depois de certo tempo, a mesma depende quase que, exclusivamente, da ação da gravidade. $A$ partir deste momento, o fluxo de entrada de água, tende a igualar-se à condutividade hidráulica do solo saturado, resultando na chamada velocidade de infiltração básica -VIB.

De um modo geral, existem diversos métodos usados para determinar a velocidade de infiltração de água dos solos, que podem ser classificados conforme Parr \& Bertrand (1960), em três grupos: 1) aqueles em 
que a velocidade de infiltração é determinada pela diferença entre a água aplicada e o escoamento superficial; 2) aqueles em que a água é colocada em uma área limitada, mantendo-se uma carga hidráulica constante; 3) aqueles em que a velocidade de infiltraçăo é obtida a partir dos dados da chuva. Contudo, em todos os grupos mencionados, os valores obtidos estão sujeitos a variações ocasionadas por fatores diversos.

0 método em que se utiliza o permeâmetro de campo está no segundo grupo e funciona pelo princípio de Mariotte, fornecendo água sob carga constante a um orifício feito no solo. Através deste método, pode-se medir a infiltração saturada a qualquer profundidade, detectando mudanças na estrutura do solo, resultante de uso e manejo (Reynolds \& Vieira, 1992).

Poggiani et al. (1983), avaliando os efeitos do fogo na brotação e crescimento de Eucalyptus grandis logo após o corte raso e as alterações nas propriedades do solo, verificaram que o solo do local de ensaio apresentou, em geral, uma taxa de infiltração elevada, porém houve evidências de que a passagem do fogo provocou uma redução na ordem de quase $50 \%$.

Arzeno (1990) ao fazer uma comparação da infiltração da água em um latossolo roxo distrófico submetido a diferentes tipos de manejo, usando um permeâmetro de campo, para medições a 15 e $50 \mathrm{~cm}$ de profundidade, detectou que a camada superior a $15 \mathrm{~cm}$ é a mais limitante. Em relação aos tipos de manejo, o autor verificou que a infiltração, no tratamento em que houve plantio direto, foi maior que aquela verificada no solo sob preparo convencional.

Terren (1993) analisando o efeito do fogo controlado na velocidade de infiltração de água em solos florestais (Pinus muricata), através de infiltrômetros cilíndricos ( $1 \mathrm{~m}$ de diâmetro), observou que seus valores, não diferiram significativamente entre as áreas não queimadas e queimadas controladamente com uma pequena intensidade de fogo.

Bertol \& Santos (1995) ao estudarem um cambissolo húmico distrófico em Lages (SC), compararam o uso do solo explorado com lavoura em preparo convencional durante quinze anos, com mata nativa, com campo nativo 
sob pisoteio de animais e florestamento de Pinnus elliottii durante quinze anos, observaram que o uso com lavouras anuais em preparo convencional durante quinze anos reduziu a taxa de infiltração em $89 \%$ em relação a mata nativa.

Baptista et al. (1996) ao analisarem as propriedades hídrico-físicoquímicas de dois tipos de solo (Cambissolo Húmico Álico e Terra Bruna Estruturada), verificaram que a taxa constante de infiltração foi maior no primeiro, provavelmente em função de seu maior teor de matéria orgânica.

Usando um simulador de chuvas, Hester et al. (1997) avaliaram as características hidrológicas de alguns tipos de vegetação (carvalho, junipero, arbusto e pasto), quando queimados e não queimados. Os autores verificaram que a taxa de infiltração em áreas não queimadas foi maior para os solos sob todos os tipos de vegetação; sendo, significativamente, maior em locais dominados por carvalho e junipero.

\subsection{Mesofauna}

Anderson (1975), afirma que o solo apresenta algumas das comunidades mais ricas em espécies da natureza. Solos sob florestas temperadas podem conter até milhares de espécies de animais edáficos, incluindo centenas de espécies de ácaros e colêmbolos. Os pequenos animais do solo desempenham função importante nos ecossistemas florestais, nos processos de degradação de matéria orgânica, dos elementos da liteira, aumentando a área exposta à ação de bactérias e fungos (Witkamp \& Olson, 1963). Segundo Fitkau e Klinge (1973), a grande diversidade da fauna e da flora existente na floresta amazônica é o fator essencial para a eficiência da retenção de nutrientes.

A maioria dos componentes da mesofauna e muitos da macrofauna melhoram o solo, especialmente, no que diz respeito à mobilização 
de nutrientes através de enzimas do melhoramento da estrutura e através da ativação da microvida. Em parte, melhoram os atributos físicos através do revolvimento. As galerias construídas pelos pequenos animais do solo, como insetos, minhocas e outros, proporcionam a penetração das raízes, a infiltração da água e a circulação do ar. A atividade da mesofauna deve ser considerada conjuntamente à dos microrganismos do solo, já que, a primeira cria condições favoráveis para a microvida e a controla (Primavesi, 1990).

Poggiani et al. (1996), afirmam que em relação à população de animais no solo, em solos florestais, a meso e macrofauna, devido a sua importância, são os mais freqüentemente estudados.

Muitas espécies de ácaros de vida livre são predadoras, podendo ser encontradas na camada da matéria orgânica que recobre o solo, alimentando-se de pequenos artrópodes, nematóides e outrōs ácaros. Algumas destas espécies apresentam hábito micófago, e podem se alimentar de fungos que se desenvolvem na matéria orgânica (Flechtmann, 1975).

A lavração, a queimada, a exposição do solo ao sol e o uso de adubos amoniacais fazem com que a maioria da mesofauna desapareça (Primavesi, 1990).

Teixeira \& Schubart (1988), estudando a mesofauna do solo em áreas de floresta e pastagem na Amazônia Central, observaram que a queima da biomassa vegetal da floresta, provoca a morte de grande quantidade de animais, reduzindo a diversidade faunística do solo. Observaram também que os grupos de ácaros e colêmbolos predominam em números de indivíduos por $\mathrm{m}^{2}$, tanto no ecossistema de floresta quanto no ecossistema de pastagem, apesar de não terem encontrado diferenças na densidade média da fauna para os dois tipos de ecossistemas. Outra observação dos mesmos autores foi que em pastagens de Brachiaria humidicula houve recolonização da área por grande parte dos grupos de animais do solo, devido, principalmente, aos 
refúgios formados por grandes troncos e fornecimento de nutrientes e energia pela liteira da graminea e excrementos dos animais.

Luff \& Hutson (1977) citaram que três estágios estão envolvidos no desenvolvimento da fauna do solo em uma paisagem virgem: 1) imigraçäo; 2) estabelecimento da população; 3) manutenção da população. $O$ primeiro requer espécies com habilidade dispersiva. Para o segundo, alimento, habitat favorável e cobertura vegetal devem ser avaliados. Já para o terceiro estágio, manutenção da população; a população estabelecida deve ser capaz de sobreviver às variaçōes sazonais e de curto prazo no ambiente.

Sautter \& Santos (1994) avaliando a estrutura de população de mesofauna concluíram que os colêmbolos só foram encontrados em áreas com cobertura vegetal, demonstrando assim sua necessidade de disposição de alimento e habitat favorável para o estabelecimento em um local de paisagem recém recomposta.

Sautter \& Trevisan (1994) estudando a população de oribatei e colêmbolos em sítios sob povoamento de Pinus taeda $L$, concluíram que estes organismos demonstraram ser mais numerosos em sítio, no qual a camada de material orgânico é maior; sendo assim, influenciados pela quantidade e qualidade do material orgânico depositado.

Sautter et al. (1994) realizando uma pesquisa para avaliar a população de oribatei, colêmbolos e oligoqueta observaram que os colêmbolos demonstraram ser mais sensíveis aos regimes de reabilitação, necessitando para estabelecimento em um local de paisagem recém decomposta, de disponibilidade de alimento e habitat favorável. Verificaram também que os fatores de umidade do solo e maior quantidade de matéria orgânica favorecem o aumento da população de ácaros e colêmbolos.

Parece existir uma relação especifica entre os animais de um certo solo e suas condições pedológicas, pois, à medida que as condições físicas e químicas de um solo tornam-se desfavoráveis, diminui a relação entre 
ácaros e colêmbolos, e quanto mais adensado e inóspito o solo, tanto menor se torna a população acariana (Primavesi, 1990).

Lima et al. (1992) detectaram que a micro e mesofauna diminuem com a aumento da intensidade de preparo do solo, devido a diminuição das quantidades de matéria orgânica do solo.

Como a mesofauna diversificada depende da presença de matéria orgânica no solo e de seu adequado arejamento, a decadência física contribui para o desaparecimento da maioria dos animais do solo, restando somente algumas espécies que suportam condições adversas e que têm a sua proliferação garantida devido à falta de inimigos naturais. Em solos com mesofauna abundante, o húmus produzido sempre é de boa qualidade, melhorando a capacidade de troca catiônica (CTC) do solo. Não se observa a formação de húmus ácido em solos com atividade animal diversificada. Os animais transformam a matéria orgânica, pré digerindo-a, de modo que possa ser atacada diretamente por microrganismos decompositores. Onde existe uma meso e macro fauna ativa, há menos fungos no solo, havendo portanto menor perigo de doenças fúngicas (Brady, 1989 e Primavesi, 1990)

\subsection{Ecossistema de Cerrado}

A área sob vegetação de cerrado ocupa 200 milhões de hectares, ou cerca de $23 \%$ do Brasil, estendendo-se principalmente pelas regiões Centro Oeste, Nordeste e Sudeste. Em termos comparativos, pode-se mencionar que o ecossistema de cerrado ocupa uma área superior a dois terços da área coberta pela Floresta Amazônica, sendo portanto o segundo ecossistema brasileiro em termos de dimensão (Goedert, 1989).

Dentro da classificação geral da vegetação dos cerrados, distinguem-se, geralmente quatro tipos de vegetação, tomando-se por base 
aspectos ecológicos e fisionômicos e seguindo uma ordem crescente de produção de biomassa arbustiva ou arbórea: campo limpo, campo cerrado, cerrado e cerradão (Lopes, 1983). No entanto, segundo EMBRAPA (1975), os três primeiros grupos se enquadram no grande grupo das formaçōes campestres e o quarto, nas formações florestais.

Para Coutinho (1990), diversas são as formações que compõem o complexo dos cerrados brasileiros, tais como campos limpos, campos sujos, campos cerrados, cerrados e cerradōes. O primeiro apresenta apenas um estrato herbáceo/subarbustivo. Nos outros três, o estrato lenhoso vai gradativamente adquirindo maior importância na paisagem; sendo que o cerradão apresenta-se como uma florestas com as copas das árvores se tocando e gerando sombra, enquanto que o extrato herbáceo/subarbustivo é muito pobre e rarefeito. Estas formações estão sujeitas, em diferentes graus, a um fator ambiental comum: o fogo.

O cerrado é considerado por Hueck (1972), como sendo uma vegetação primária remanescente de um revestimento florístico antigo, que era mais difundido e teve seu centro de difusão no Brasil Central. Para o autor, após mudanças nas condições climáticas ocorreu uma invasão da vegetação circundante, e hoje, aparecem os cerrados em certos locais como "ilhas" de uma vegetação antiga, remanescentes em meio dos seus arredores.

Para Ferri (1973), em certos locais, os cerrados foram originados de causas naturais e, em outros, decorrente da ação antropogênica. Para o autor, a partir da devastação da vegetação primária desses locais, houve a ocupação de uma vegetação com outras exigências, como a do cerrado, por exemplo; sendo que não foi permitido o retorno. Desse modo, uma floresta pode recuperar uma área invadida por cerrado, desde que cesse a devastação pelo homem.

Vários autores, como Alvim (1954), afirmam que a causa principal do surgimento do cerrado é a deficiência de minerais, ou seja, a composição 
química do solo, que é função, principalmente, de uma origem geológica. 0 fogo seria apenas uma causa secundária.

Em relação aos aspectos climáticos, em $65 \%$ da superfície da região são registradas precipitaçōes anuais entre $1200 \mathrm{~mm}$ e $1600 \mathrm{~mm}$, em $86 \%$ dessa superfície chove ente $1000 \mathrm{~mm}$ e $2000 \mathrm{~mm}$ anuais (Adamoli et al., 1986). Porém, não há uma boa distribuição das chuvas durante o ano. A estação seca que caracteriza a região também apresenta uma distribuição heterogênea quanto a sua intensidade e duração (Goedert, 1989). Segundo Adamoli et al. (1986), $88 \%$ da superfície desses ecossistemas apresenta um período de 4 a 7 meses de déficit hídrico. Goedert (1989) relatam que a temperatura média anual situa-se entre $22^{\circ} \mathrm{C}$ ao Sul e $27^{\circ} \mathrm{C}$ ao Norte. Devido às características tropicais do cerrado, existem condições de isotermia, pois as diferenças entre temperaturas máximas e mínimas oscilam entre $4^{\circ} \mathrm{C}$ e $5^{\circ} \mathrm{C}$.

Os latossolos são os solos predominantes sob vegetação de cerrado e caracterizam-se pela baixa fertilidade natural (Demattê \& Demattê, 1993). Quanto à textura, segundo Coutinho (1990), os solos são mais freqüentemente areno-argilosos ou argilo-arenosos, com razoáveis graus de permeabilidade, porosidade e arejamento. Calle \& Vellasco (1977), afirmam que o cerrado apresenta um equilíbrio entre a vegetação, solo, microrganismos e clima; por isso, qualquer modificação do ecossistema irá alterar o processo de humificação em função das peculiaridades da decomposição dos resíduos orgânicos. Para Goedert et al. (1989), devido a baixa fertilidade natural do solo desse ecossistema, o mesmo exige um manejo adequado.

Ao caracterizarem química e bioquimicamente solos sob vegetação de mata e campo cerrado adjacente, Fernandes et al. (1997), concluíram que qualquer interferência que altere a matéria orgânica do solo e sua dinâmica, exercerá enorme influência sobre as propriedades químicas e bioquímicas com reflexos na fertilidade do solo e na sustentabilidade dos ecossistemas. 


\subsection{As plantações florestais de eucalipto}

O gênero Eucalyptus, pertence à família Myrtaceae que contém cerca de 90 gêneros e mais de 3000 espécies. O Eucalyptus, é um gênero, originário da Austrália, onde ocorrem cerca de 600 espécies e variedades que são endêmicas no país; aparecendo também em Timor e em algumas ilhas adjacentes como Flores, Alor, Solor e Wetar (Prior, 1976).

Para Sansigolo et al. (1983), devido a sua alta produtividade em um período relativamente curto, quando comparado com espécies florestais nativas, o gênero Eucalyptus, tornou-se economicamente importante para o Brasil. Em relação a isso, Moura et al. (1992) afirmam que Eucalyptus grandis Hill ex. Maiden, por seu crescimento, forma e alguns aspectos tecnológicos, é uma das espécies preferidas para reflorestamento e, sem dúvida nenhuma, a mais difundida no Brasil.

Balloni (1979) levanta algumas preocupações no que diz respeito a exportação de nutrientes, devido a utilização de resíduos de espécies florestais (folhas, ramos e cascas), pois, sendo os reflorestamentos implantados em solos de baixa fertilidade, a maior proporção dos elementos contidos nestes resíduos não mais retornam ao solo. Devido a estas práticas, Sansigolo et al. (1983), afirmam que ocorrem alterações bruscas no ciclo de nutrientes de uma floresta que podem refletir negativamente na fertilidade do solo.

Haag et al. (1978) e Sansigolo et al. (1983) afirmam que uma floresta adulta deposita anualmente no solo grande quantidade de matéria orgânica e suas raízes são capazes de extrair elementos minerais das camadas mais profundas, favorecendo a ciclagem de nutrientes. Pacífico Homem (1961), ressalta que é da ordem de $15.000 \mathrm{~kg} \mathrm{ha}^{-1} \mathrm{ano}^{-1}$, a quantidade de matéria orgânica deixada em solo sob eucalipto. Rocha Filho et al. (1978), concluíram que o E. citriodora exerce influencia positiva sobre o teor de carbono no solo. Por outro lado, alguns pesquisadores consideram o eucalipto uma cultura que diminui a fertilidade do solo, inibe a fauna e a flora e, até mesmo, como 
causadora do desequilibrio de mananciais (Fonseca, et al. 1993). Esses mesmos autores, tendo como referência as condições prevalecentes sob florestas naturais, concluíram que tanto o eucalipto como a pastagem, provocam grandes alterações nas características químicas e físicas do solo. Della Bruna et al. (1989), chamam a atenção para a possibilidade de prejuizos causados ao solo e à sua microbiota. Estes prejuízos são visualizados pela inibição do crescimento de espécies nativas e acúmulo de material orgânico não decomposto sobre o solo, o que, segundo Florenzano (1957), são devidos à baixa atividade microbiana causada pela presença de substâncias inibidoras de crescimento e da atividade da microbiota do material em decomposição.

O acúmulo do material orgânico sobre o solo é função da quantidade de queda da liteira e da taxa de decomposição. Em monoculturas, como de Pinus e Eucalyptus, tem-se observado grande acúmulo de resíduos, em comparação com as florestas nativas, o que se deve, principalmente à dificuldade na decomposição do material. Com os reflorestamentos homogêneos, tanto de espécies nativas quanto de exóticas, observa-se uma alteração na forma e na qualidade da matéria orgânica acumulada em relação à mata nativa. Esta nova forma de acúmulo, de certo modo seletivo, possui uma dinâmica diferente para cada espécie florestal. Este aspecto em particular, pode a longo prazo, afetar de modo distinto as propriedades físicas, químicas e biológicas do solo (Reissmann, 1983).

Ao analisarem a atividade da microbiota de solos adicionados de serapilheira de eucalipto e de nutrientes, Della Bruna et al. (1991), verificaram que em amostras do solo sob mata nativa, a atividade da microbiota foi maior quando comparado ao solo sob eucalipto. 


\section{MATERIAL E MÉTODOS}

\section{1 Área de estudo}

O estudo foi conduzido em áreas da Fazenda Entre Rios, pertencente a Companhia Suzano Papel e Celulose, município de Itatinga, Estado de São Paulo. As coordenadas geográficas do local são: altitude de $649 \mathrm{~m}$, latitude de $23^{\circ} 17^{\prime}$ ao Sul e longitude de $48^{\circ} 26^{\prime}$ a Oeste.

\subsubsection{Condições climáticas}

De acordo com a classificação de KÖEPPEN, o clima da região é Cwa, ou seja, mesotérmico de inverno seco, sendo a temperatura média do mês mais frio (julho) inferior a $18^{\circ} \mathrm{C}$; e a do mês mais quente (janeiro) superior a $22^{\circ} \mathrm{C}$. O total de chuvas no mês mais seco não ultrapassa $30 \mathrm{~mm}$. A precipitação média anual da área é de, aproximadamente, $1579 \mathrm{~mm}$, com $57 \%$ concentrada nos meses de dezembro a março. Não se observa déficit hídrico. $\mathrm{Na}$ Figura 1 é apresentado o balanço hídrico da área em que o presente estudo foi desenvolvido, no período de janeiro a dezembro de 1997. 


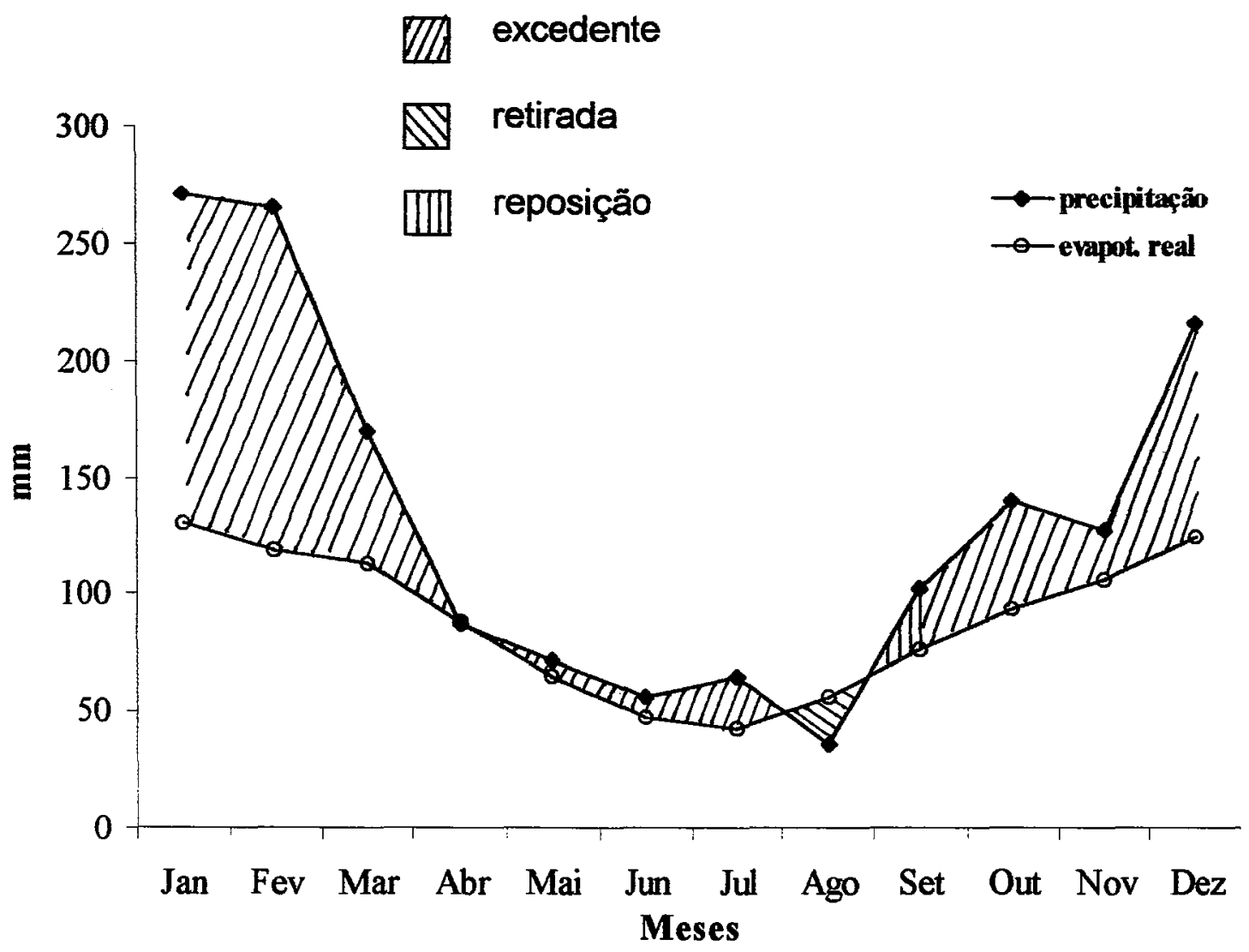

Figura 1 - Balanço hídrico, segundo Thornthwait \& Mather (1955), considerando o período de janeiro a dezembro de 1997 e $125 \mathrm{~mm}$ de capacidade de armazenamento de água do solo. 


\subsubsection{Condições edáficas}

O solo da área experimental é classificado como latossolo vermelho-amarelo, textura média, distrófico, com relevo plano a suave ondulado. Apresenta fertilidade muito baixa, $\mathrm{pH}$ de aproximadamente 3,5 e predominância da fração areia ( $78 \%$ de areia, $15 \%$ de argila e $7 \%$ de silte)

\subsubsection{Condições florísticas}

A vegetação natural da área era o cerrado, porém atualmente existem também extensos blocos de florestas plantadas (eucalipto).

\section{2 - Definição dos Tratamentos}

O experimento foi desenvolvido no talhão 80 , que consiste em um povoamento de Eucalyptus grandis Hill Ex Maiden sob diferentes tipos de práticas de manejo do solo e em área próxima onde ainda é mantida a vegetação natural (cerradão).

As práticas de manejo estudadas no talhão 80 , foram:

a) Tipo de Manejo A (TMA) - Manutenção do povoamento intacto de Eucalyptus grandis, com aproximadamente 9 anos de idade;

b) Tipo de Manejo C (TMC) - Corte raso do povoamento, mantendo todos os residuos culturais na superfície do solo (Cultivo Mínimo);

c) Tipo de Manejo E (TME) - Corte raso do povoamento, removendo todos os resíduos culturais da superfície do solo;

d) Tipo de Manejo F (TMF) - Corte raso do povoamento, incorporando todos os resíduos culturais no solo através de dois repasses de uma grade; 
e) Tipo de Manejo G (TMG) - Corte raso do povoamento, distribuindo todos os resíduos culturais, com posterior queima.

Em julho de 1995 foi realizado o corte raso do povoamento de eucalipto para a implantação do experimento, deixando uma área intacta. Os tratamentos (tipos de manejo), foram instalados em agosto de 1995. Um mês após a instalação dos mesmos, foi realizado o plantio de novas mudas de Eucalyptus grandis formadas a partir de sementes. $O$ plantio foi feito em sulco de $30 \mathrm{~cm}$ de profundidade, no espaçamento de $3,0 \mathrm{~m} \times 2,0 \mathrm{~m}$.

\subsection{Delineamento experimental}

No estudo do desprendimento de $\mathrm{CO}_{2}$, adotou-se o delineamento de blocos ao acaso em parcelas subdivididas, sendo que os tratamentos principais foram as práticas de manejo (TMA, TMC, TME, TMF e TMG), e os tratamentos secundários as épocas de medição (junho de 1997 a fevereiro de 1998). No cerradão, adotou-se o delineamento experimental inteiramente casualizado.

A avaliação da velocidade de infiltração de água no solo foi realizada, adotando-se o delineamento em blocos ao acaso no esquema fatorial de $5 \times 2$, com 4 blocos (repetições). 0 primeiro fator foi o tipo de manejo com 5 niveis (TMA, TMC, TME, TMF e TMG) e o segundo fator, foram as profundidades $(6$ e $20 \mathrm{~cm}$ ) em que foram realizadas as mediçōes. No cerradão adotou-se o delineamento experimental inteiramente casualizado.

A quantificação da mesofauna do solo no povoamento de eucalipto, foi realizada somente no bloco II (TMA, TMC, TME e TMG). Adotouse o delineamento experimental inteiramente casualizado com 3 repetições tanto nesta área quanto na de cerradão.

Na Figura 2, é apresentado o croqui da área experimental do povoamento de eucalipto. 


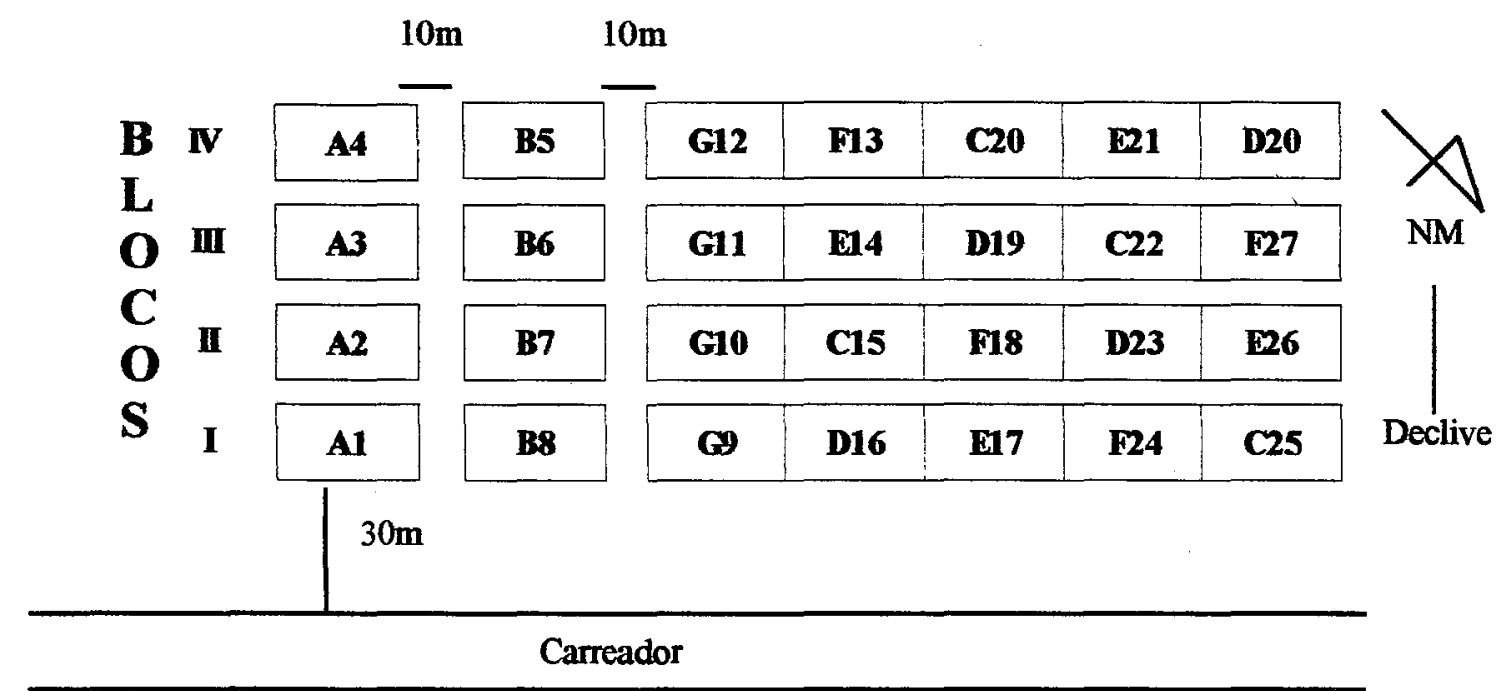

Figura 2 - Croqui da área experimental, apresentando a distribuição dos tipos de manejo, em que: $A \rightarrow$ Manutenção do povoamento de eucalipto (com aproximadamente 9 anos); $\mathrm{B}^{*} \rightarrow$ Manutenção dos restos culturais na superfície do solo, após o corte raso e condução da rebrota; $\mathrm{C} \rightarrow$ Manutenção dos restos culturais na superfície do solo e reforma (replantio), após o corte raso; $\mathbf{D}^{*} \rightarrow$ Remoção dos restos culturais e manutenção da serapilheira (replantio), após o corte raso; $E \rightarrow$ Remoção dos restos culturais e serapilheira (replantio), após o corte raso; F $\rightarrow$ Incorporação dos restos culturais e serapilheira com gradagem (replantio), após o corte raso; $G \rightarrow$ Queima dos restos culturais (replantio), após o corte raso. 
No povoamento de eucalipto, houve uma restrição à aleatorização dos tratamentos (tipos de manejo) onde houve a queima e onde permanece a área intacta.

\subsection{Liberação de $\mathrm{CO}_{2}$}

As taxas de liberação de $\mathrm{CO}_{2}$ foram medidas mensalmente (junho de 1997 a fevereiro de 1998), durante 12 horas no período noturno (das 18 às 6 horas do dia seguinte). Isso foi feito porque à noite a temperatura oscila menos, podendo ser melhor observado o efeito dos tratamentos. Para realizar a medição, foram distribuídos na área experimental, pequenos suportes de madeira, sobre os quais foram colocados recipientes de vidro contendo $20 \mathrm{~mL}$ de $\mathrm{NaOH}$ a $0,5 \mathrm{~mol} \mathrm{~L}^{-1}$. Estes conjuntos foram então encobertos por campânulas (baldes plásticos com $25 \mathrm{~cm}$ de diâmetro). Foram distribuidos 12 conjuntos em cada tipo de manejo no povoamento de eucalipto e 6 no cerradão, sendo que as bordas dos baldes, foram deixadas rentes ao solo, colocando dois tijolos em cima de cada um. Isso foi feito para evitar trocas gasosas diretamente com a atmosfera. Cada recipiente de vidro contendo a solução de $\mathrm{NaOH}$ foi destampado para que fixasse $\circ \mathrm{CO}_{2}$ liberado do solo, sendo que um recipiente (branco) permaneceu tampado, porém recebeu o mesmo tratamento que os demais. Após 12 horas de permanência no local, as campânulas foram retiradas, e os recipientes foram rapidamente tampados e levados ao laboratório. Na Figura 3 é mostrado o desenho esquemático da respirometria no campo.

A quantificação do $\mathrm{CO}_{2}$ desprendido do solo foi feita mediante titulação do $\mathrm{NaOH}$ remanescente nos recipientes, com uma solução de $\mathrm{HCl}$ a $0,5 \mathrm{~mol} \mathrm{~L}^{-1}$. A massa de $\mathrm{CO}_{2}$ desprendido por unidade de área e tempo, foi obtida considerando a massa total desprendida no período de permanência na área (obtida por titulação) e a área de abrangência da campânula, como mostra 
a equação seguinte:

$\mathrm{CO}_{2}\left(\mathrm{mg} \mathrm{m}^{-2} \mathrm{~h}^{-1}\right)=\frac{\left(\mathrm{V}_{\mathrm{B}}-\mathrm{V}_{\mathrm{A}}\right) \mathrm{N}_{\mathrm{HCl}} \times \mathrm{EqCO}_{2}}{\mathrm{~A} \times 12}$

Em que:

$\mathrm{V}_{\mathrm{B}}$ : volume do ácido clorídrico gasto na titulação do branco ;

$\mathrm{V}_{\mathrm{A}}$ : volume do ácido clorídrico gasto na titulação da amostra;

$\mathrm{N}_{\mathrm{HCl}}$ : normalidade do ácido clorídrico $=0,5$;

$\mathrm{Eq} \mathrm{CO}$ : equivalente grama do $\mathrm{CO}_{2}=22$;

A: área de abrangência da campânula $=0,049 \mathrm{~m}^{2}$;

12: fator de correção (transformação para hora)

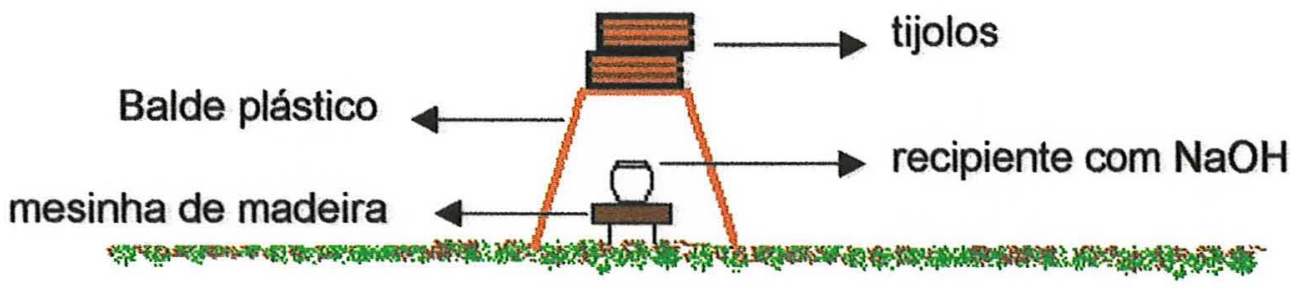

Figura 3 - Desenho esquemático do método utilizado para medir a respirometria no campo 


\subsection{Velocidade de infiltração de água no solo}

Para medir a taxa constante da infiltração de água no solo foi utilizado um aparelho denominado permeâmetro de campo (Figura 4). Seu funcionamento baseia-se no princípio de Mariotte, fornecendo água para um orifício no solo, com carga hidráulica controlada. Com base nos resultados obtidos, foi calculada a velocidade de infiltração básica (Reynolds \& Elrick, 1987).

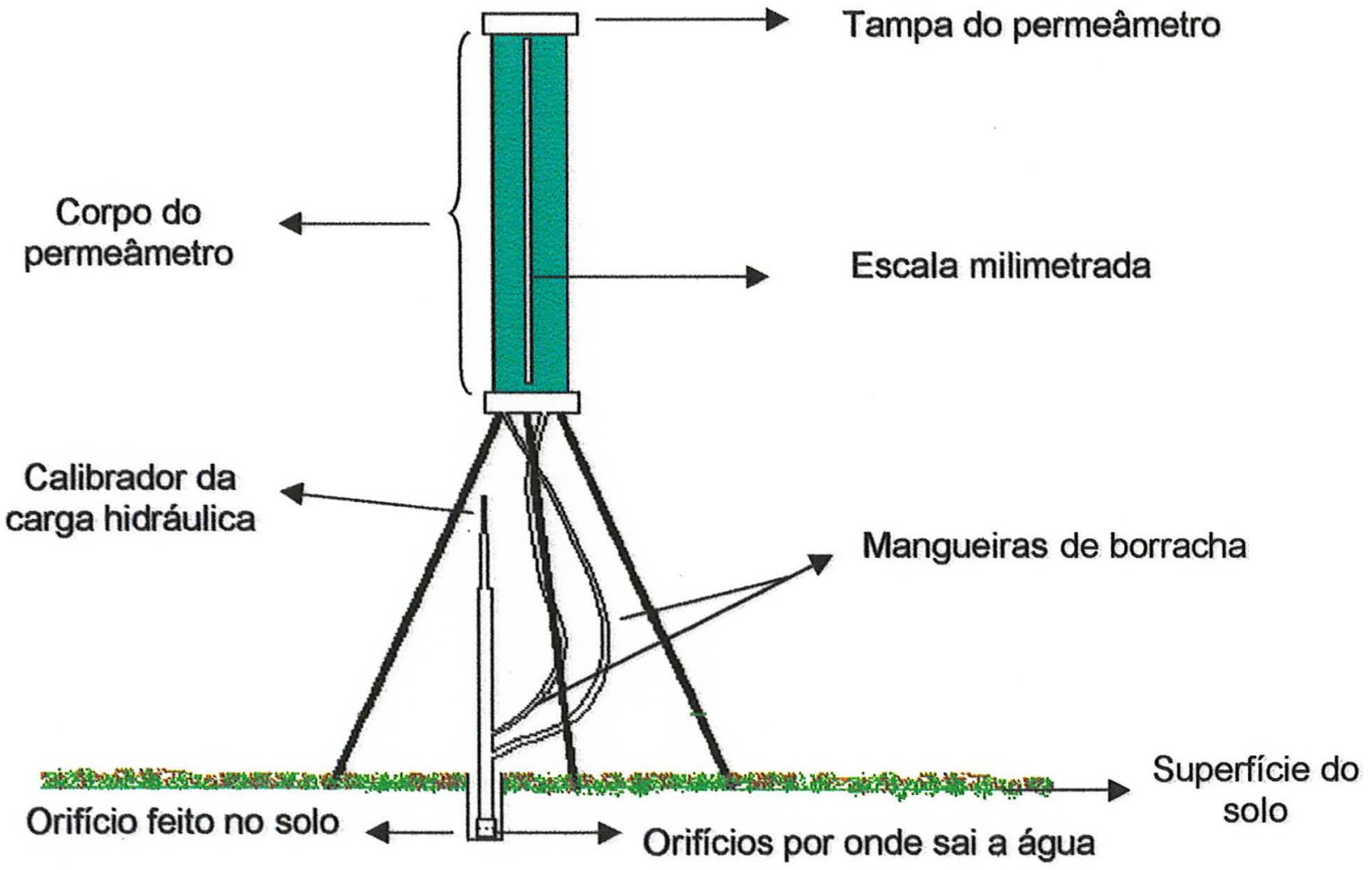

Figura 4 - Desenho esquemático do Permeâmetro de campo 
As medições foram feitas em setembro de 1997, a 6 e $20 \mathrm{~cm}$ de profundidade. Tomaram-se 3 mediçōes para cada profundidade em cada parcela. Utilizou-se um trado de caneca para fazer os orifícios e um trado limpador para que estes orificios apresentassem formato cilindrico e base plana. O permeâmetro, preenchido com água e aferido, foi colocado verticalmente sobre o orifício, sustentado por um tripé, evitando-se possiveis perturbações externas ao mesmo. $O$ início da medição se deu, aplicando-se uma carga hidráulica de $3 \mathrm{~cm}$. Após a descida da água, iniciou-se a contagem do tempo, sendo as leituras efetuadas em determinados instantes até que o fluxo se tornasse constante. Em seguida, a carga hidráulica foi elevada para 6 $\mathrm{cm}$, repetindo a operação.

A velocidade de infiltração de água no solo foi obtida, através da seguinte fórmula:

$$
I\left(m m h^{-1}\right)=\frac{D_{p}^{2}}{\left(D_{0}^{2}+D_{0} H\right)} \times Q \times 60
$$

\section{Em que:}

I: velocidade de infiltração básica (VIB)

$\mathrm{D}_{\mathrm{p}}$ : diâmetro do permeâmetro $(\mathrm{cm})$

$\mathrm{D}_{\mathrm{o}}$ : diâmetro do orifício do solo feito com o trado $(\mathrm{cm})$;

$\mathrm{H}$ : carga hidráulica $(\mathrm{cm})$;

Q: fluxo constante ( $\left.\mathrm{mm} \mathrm{min}^{-1}\right)$;

60: fator de correção (transformação de minuto para hora).

\subsection{Mesofauna do solo}

Amostras de solo+liteira foram coletadas com o emprego de anéis metálicos (diâmetro $=4,8 \mathrm{~cm}$ e altura $=5,2 \mathrm{~cm}$ ) no mês de agosto de 1997, 
coletando-se 3 amostras em cada tipo de manejo (com exceção do TMF) no povoamento de eucalipto e 3 no cerradão. Uma vez coletadas, as amostras foram levadas ao laboratório, onde procedeu-se a extração das populações constituintes da mesofauna, através do método de Berlese-Tullgren, com pequena modificação. O método consiste na migração descendente dos insetos da amostra do solo, devido à elevação da temperatura provocada pelas lâmpadas, na superfície do solo. Os insetos caem no funil e posteriormente no recipiente contendo o líquido coletor (álcool a 80\%). Na Figura 5, é apresentado um esquema do extrator usado.

A principal limitação deste método é que, permite apenas a detecção de formas móveis, não sendo possível a de ovos (Solomon, 1945). No entanto, é considerado um método conveniente e barato para a extração da mesofauna de solo de um grande número de amostras (Sinha, 1964).

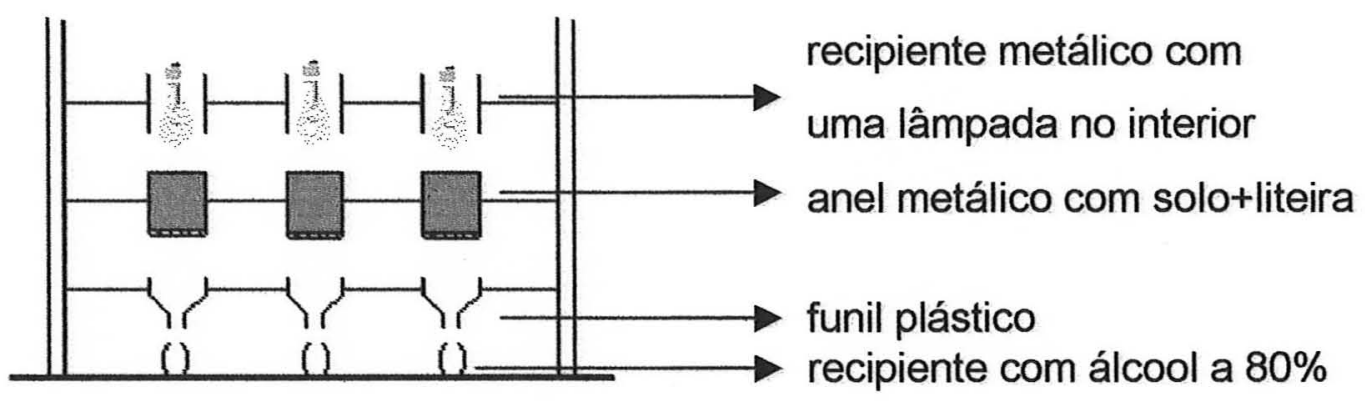

Figura 5 - Esquema do extrator da mesofauna do solo

\subsection{Dados meteorológicos, temperatura e umidade do solo e fertilidade}

Durante todo o período experimental, foram registrados diariamente dados pluviométricos e as temperaturas máximas e mínimas do ar através de instrumentos de uma estação meteorológica, situada na Fazenda Entre-Rios. 
Em todos os tratamentos, foram medidas as temperaturas máxima e mínima do solo a $2,5 \mathrm{~cm}$ de profundidade. A umidade do solo das áreas experimentais foi avaliada mensalmente, pelo método gravimétrico, mediante a coleta de amostras a $5 \mathrm{~cm}$ de profundidade, segundo EMBRAPA (1997).

Amostras de solo coletadas nas profundidades de 0-2, 2-5, 5-10 e $10-20 \mathrm{~cm}$ em todos os tipos de manejo do povoamento de eucalipto foram analisadas quimicamente quanto ao $\mathrm{pH}$, carbono orgânico, fósforo disponível, cálcio, magnésio, potássio e alumínio trocáveis e acidez potencial, utilizando-se os métodos descritos por Raij et al. (1987).

\subsection{Análise dos dados}

Os dados obtidos para todas as variáveis foram inicialmente submetidas à análise exploratória, utilizando técnicas descritas por Alves et al. (1993). Houve heterogeneidade de variância, por isso os dados originais referentes à liberação de $\mathrm{CO}_{2}$ e velocidade de infiltração de água no solo, sofreram transformação. Para a primeira variável, a transformação foi: $x=1 / y(x$ = dado transformado e $y=$ dado original) e para a segunda: $x=\ln (y)(x=$ dado transformado e $y=$ dado original).

Para as variáveis $\mathrm{CO}_{2}$ e velocidade de infiltração de água no solo no povoamento de eucalipto, foi realizada a análise de variância e teste $F$ (Anexos $\mathrm{A}$ e $\mathrm{C}$ ). As médias de liberação de $\mathrm{CO}_{2}$ foram comparadas através do teste de Tukey ao nível de 5\%. A população da mesofauna edáfica, por se tratar de uma variável aleatória discreta, foi comparada através do teste $\chi^{2}$ (Anexos D e E). Para a comparação entre o TMA do povoamento de eucalipto e a vegetação natural (cerradão), foi utilizado o teste $T$ (Anexo B). 


\section{RESULTADOS E DISCUSSÃO}

\subsection{Temperatura e umidade do solo}

As médias das temperaturas máximas e mínimas do solo medidas durante o período do experimento, são mostradas na Tabela 1. No povoamento de eucalipto, a temperatura máxima oscilou entre 27,4 e $37,8^{\circ} \mathrm{C}$, e a mínima entre 1,7 e $18,1^{\circ} \mathrm{C}$. $\mathrm{O}$ solo sob TMF (incorporação de todos os resíduos culturais ao solo) e o TMA (povoamento intacto de eucalipto - 9 anos) apresentaram as menores amplitudes térmicas em relação ao solo sob o TME (remoção de todos os resíduos culturais e serapilheira). Além de maior amplitude, O TME apresentou também maiores médias para a temperatura máxima, principalmente, nos meses mais quentes e com menor precipitaçăo pluviométrica. A remoção dos resíduos deixa o solo mais exposto ao sol e às trocas de energia.

No cerradăo, a maior temperatura máxima medida foi 30,1 (junho de 1997) e a menor $27,1{ }^{\circ} \mathrm{C}$ (dezembro de 1997). Em todos os meses avaliados, o cerradão apresentou uma menor oscilação de temperatura e uma maior umidade de solo (Tabela 2) do que o povoamento de eucalipto, considerando todos os tipos de manejo. Isso ocorre porque o cerradão apresenta um dossel vegetal que funciona como uma barreira tanto para a radiação que o atinge, como quanto para aquela que é emitida pelo solo, o que resulta no estabelecimento de um microclima mais estável em seu interior.

Com relação à umidade do solo, as maiores médias para o povoamento de eucalipto, foram observadas no TMC (manutenção de todos os resíduos culturais na superfície do solo) e TMF (incorporação de todos os 
resíduos culturais ao solo). No entanto, no cerradão, foram observados valores mais elevados, do que em todos os tipos de manejo do povoamento de eucalipto.

Pode-se observar também que o povoamento intacto de eucalipto e a área que foi colhida e queimada, apresentaram os menores valores de umidade do solo. A maior transpiração das árvores adultas do povoamento de 9 anos e da área queimada, onde houve melhor desenvolvimento, pode explicar a perda de água do solo.

Serrano (1997), trabalhando na mesma área experimental também encontrou dados semelhantes tanto para a temperatura como para a umidade do solo no povoamento de eucalipto, e enfatizou a importância dos resíduos vegetais na menor variação da temperatura e na conservação da umidade do solo. Outros autores como, Bragagnolo \& Mielniczuk (1990) e Salton \& Mielniczuk (1995), verificaram também que o sistema de preparo do solo afeta sua temperatura e umidade. 
Tabela 2 - Umidade do solo nos diferentes tipos de manejo estudados do povoamento de eucalipto e na vegetação natural (cerradão). Os valores apresentados são médias de 12 avaliações (3 repetições em cada uma das 4 parcelas).

\begin{tabular}{|c|c|c|c|c|c|c|}
\hline \multicolumn{7}{|c|}{ Umidade do solo (\%) a $5 \mathrm{~cm}$ de profundidade } \\
\hline Meses & TMA & TMC & TME & TMF & TMG & 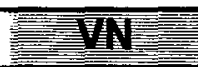 \\
\hline jun/97 & 2,8 & 3,5 & 2,9 & 3,5 & 2,6 & 46 \\
\hline jull/97 & 2,4 & 2,6 & 3,1 & 2,4 & 2,2 & 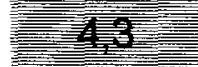 \\
\hline ago/97 & 2,4 & 2,6 & 2,2 & 2,1 & 2,2 & $39=$ \\
\hline set/97 & 3,3 & 3,3 & 3,4 & 2,7 & 2,6 & 49 \\
\hline out $/ 97$ & 2,8 & 2,6 & 3,3 & 2,7 & 2,4 & 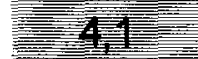 \\
\hline nov/97v & 4,6 & 7,2 & 6,5 & 7,4 & 4,8 & 65 \\
\hline $\operatorname{dez} / 97$ & 4,4 & 4,7 & 4,7 & 5,8 & 4,4 & 64 \\
\hline jan/98 & 3,2 & 3,2 & 2,7 & 2,7 & 2,4 & 6,4 \\
\hline fev/98 & 5,4 & 6,0 & 6,2 & 8,6 & 5,9 & $=0$ \\
\hline média & 3,5 & 4,0 & 3,9 & 4,2 & 3,3 & 5,5 \\
\hline
\end{tabular}

TMA: povoamento intacto; TMC: cultivo mínimo; TME: retirada dos resíduos; TMF: incorporação dos resíduos, TMG: queima dos resíduos; VN: Vegetação Natural

\subsection{A influência dos tipos de manejo do solo em sua fertilidade}

Observa-se nas Tabelas 3 e 4, que no TMC (Cultivo Mínimo) proporcionou um aumento do teor de matéria orgânica na camada de $0-2 \mathrm{~cm}$, nos dois periodos analisados (junho de 1996 e setembro de 1997). Isso pode ter ocorrido, devido às menores oscilações térmicas e hídricas do solo sob esse tipo de manejo, que favoreceu a atividade microbiana nas raizes deixadas pelas árvores do plantio anterior. Outro fato que pode explicar isso, é que as alterações do solo foram mínimas, impossibilitando grandes perdas de matéria orgânica já existente, por erosão ou mesmo lixiviação, das raízes que continuaram intactas depois do corte, sendo degradadas apenas pelos microrganismos.

Nos primeiros centimetros do solo, a queima dos resíduos culturais (TMG) promoveu um aumento dos teores de $\mathrm{Ca}, \mathrm{K}, \mathrm{Mg}$ e $\mathrm{P}$, bem como 
uma diminuição do Al trocável e de $\mathrm{H}+\mathrm{Al}$, favorecendo assim a elevação do $\mathrm{pH}$ (Tabelas 3 e 4). Resultados semelhantes foram obtidos por Serrano (1997). Essa mesma autora, ao comparar os resultados da análise química do solo logo após a aplicação dos tratamentos e depois de aproximadamente 6 meses, verificou que houve uma redução dos teores de $P$ e de bases trocáveis no solo. No entanto, neste trabalho, comparando a Tabela 3 com a Tabela 4, observa-se que no TMG o teor de $P$ permaneceu praticamente inalterado, porém houve tendência a um aumento no teor de matéria orgânica e na soma de bases. Ou seja, o fator tempo não influenciou no teor de $P$, mas influenciou, positivamente no teor de matéria orgânica e soma de bases. 


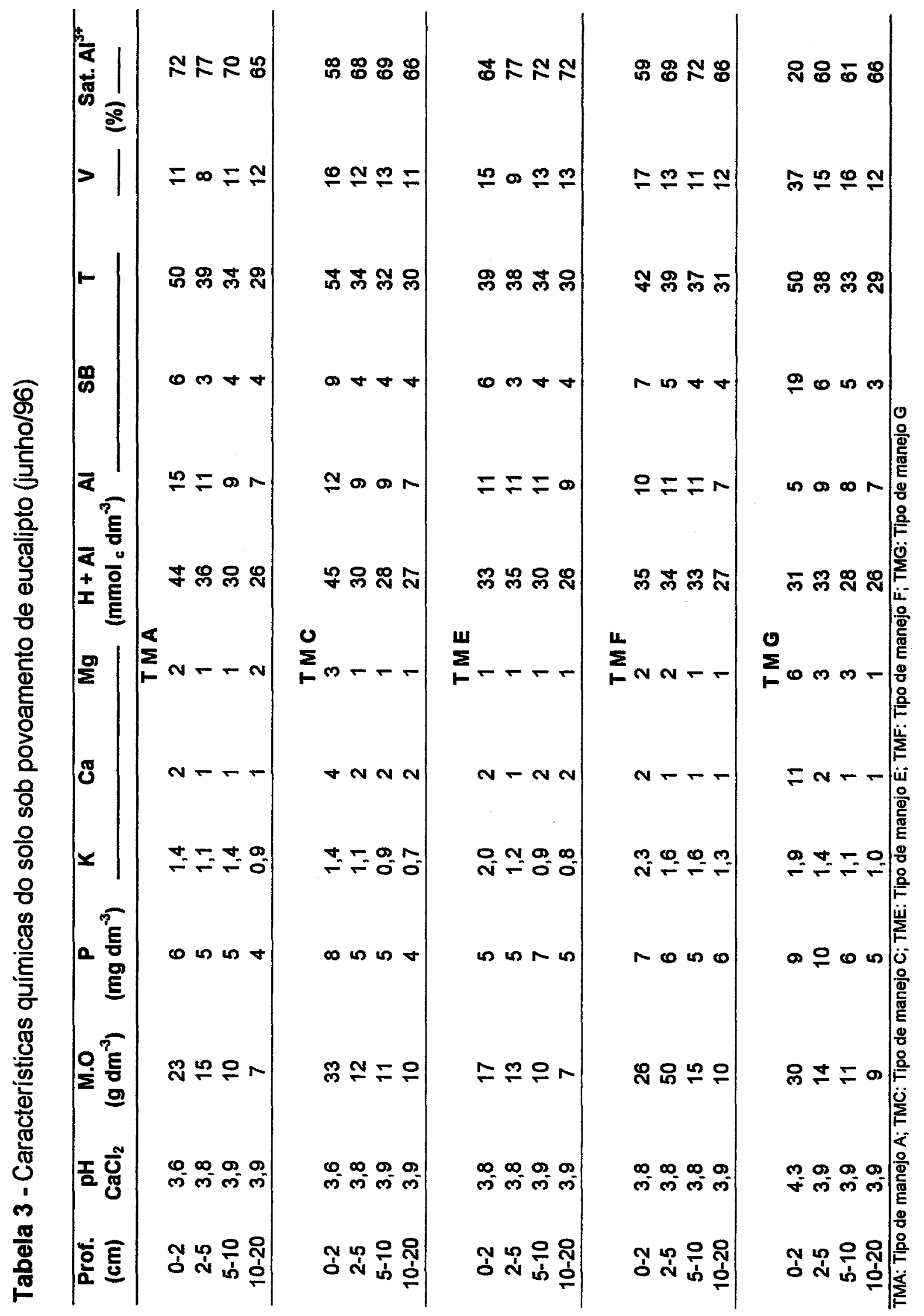




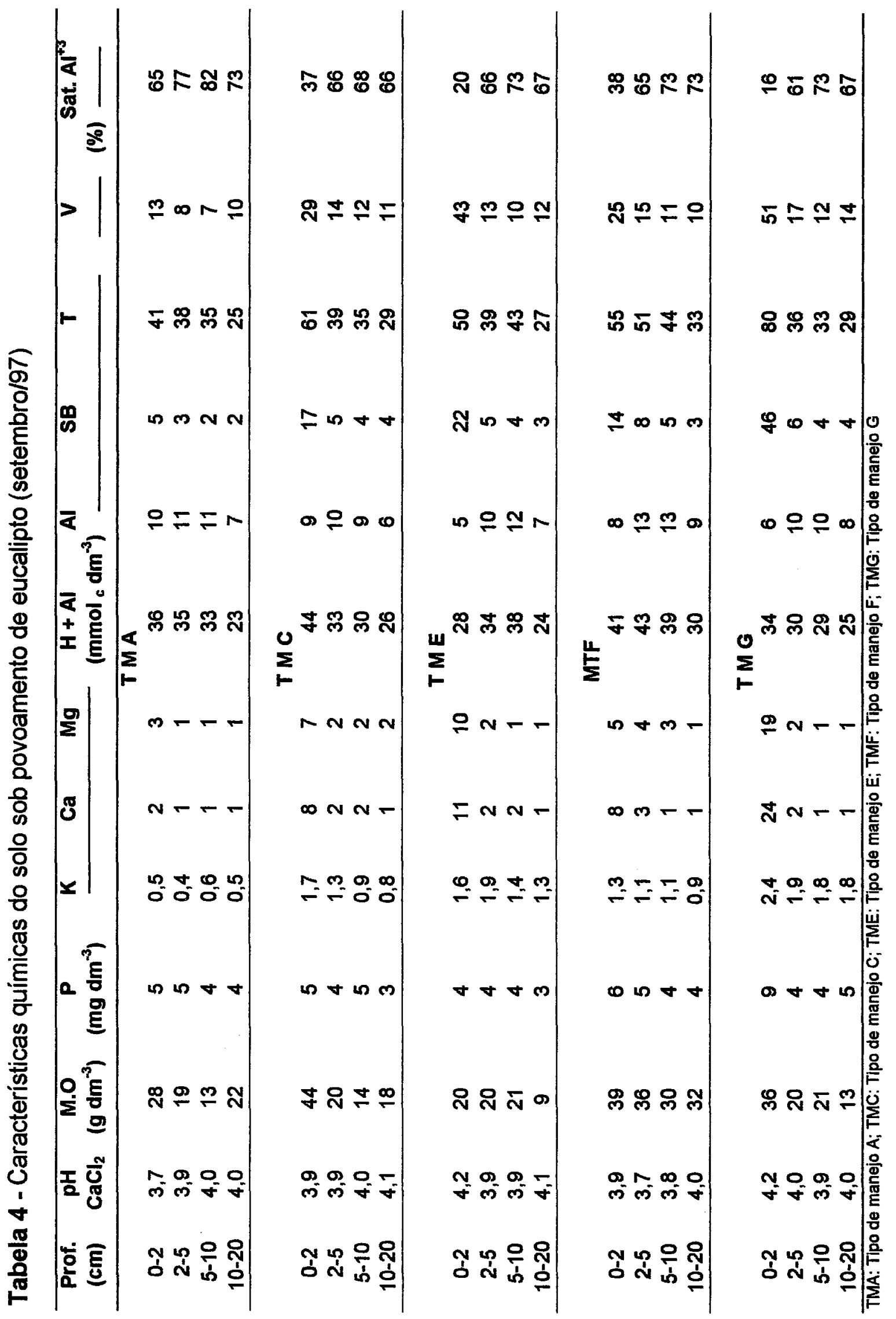




\subsection{Respirometria do Solo}

\subsubsection{Comparação entre os diferentes tipos de manejo}

Através da análise de variância para a respirometria do solo, observou-se que houve diferença significativa entre os tipos de manejo $(F=3,398, p=0,04)$ e entre as épocas de avaliação $(F=41,764, p<0,001)$. Não houve efeito significativo da interação entre o tipo de manejo e o tempo. Isso mostra que não houve dependência entre os tratamentos primários (tipos de manejo) e o secundário (tempo).

O tipo de manejo $G$ (queima de todos os resíduos culturais) apresentou a maior média de $\mathrm{CO}_{2}$ liberado e o tipo de manejo $\mathrm{A}$ (povoamento intacto de eucalipto), a menor média (Figura 6).

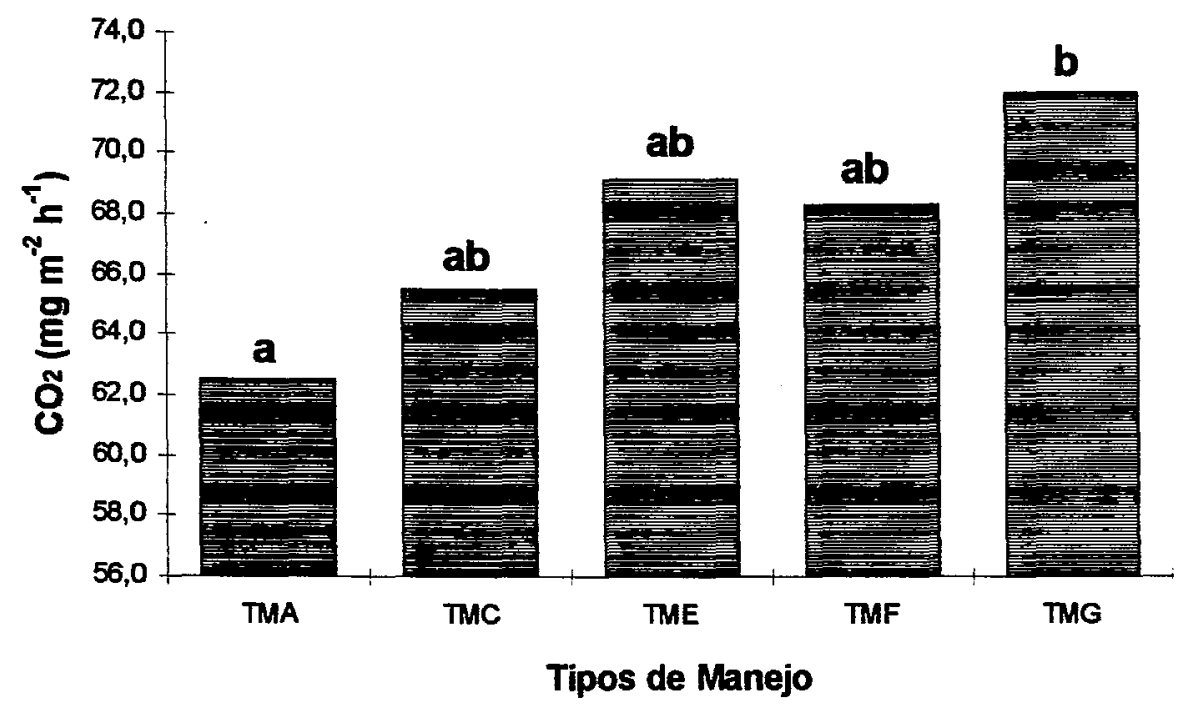

Figura 6 - Média de $\mathrm{CO}_{2}$ liberado nos diferentes tipos de manejo do povoamento de eucalipto. Médias seguidas de letras iguais, não diferem entre si pelo teste de Tukey, ao nivel de $5 \%$. 
Isso, provavelmente, pode ser atribuído ao aporte de nutrientes liberados pelas cinzas no TMG, além do maior $\mathrm{pH}$ e do menor teor de $\mathrm{Al}$. $\mathrm{O}$ aumento do "status" nutricional proporcionou um arranque das árvores $e$, consequentemente, uma maior atividade radicular (respiração das raízes), que contribuiu para o aumento do $\mathrm{CO}_{2}$ nesse tipo de manejo.

Santos e Grisi (1981), também verificaram um aumento na liberação do $\mathrm{CO}_{2}$ onde houve a queima, ressaltando que a ação do fogo sobre a fitomassa, provavelmente ocasiona mudanças nas propriedades edáficas, beneficiando os microorganismos. Porém, Poggiani et al. (1983) verificaram que em áreas de Eucalyptus grandis, a liberação de $\mathrm{CO}_{2}$ diminuiu, logo após a queima. Weber (1990), também mostra que houve um declínio na taxa de respiração do solo, em áreas cortadas e queimadas de um ecossistema imaturo.

É provável, que logo após a fogo, a atividade biológica do solo tenha sofrido um declínio devido ao efeito da queima na matéria orgânica. No entanto, com o passar do tempo, a cinza adicionada ao solo passaria a atuar como um fertilizante, incrementando a produtividade vegetal e a atividade dos microrganismos. Como este trabalho foi realizado dois anos após a passagem do fogo na área, acredita-se que já houve tempo para o reestabelecimento dos microrganismos, o que justifica as elevadas taxas de $\mathrm{CO}_{2}$ observadas para esse tipo de manejo.

A maior liberação de $\mathrm{CO}_{2}$ se deu durante o período de final da primavera e todo o verão (novembro de 1997 a fevereiro de 1998). No mês de janeiro de 1998, todavia, houve uma queda. No entanto, ainda assim o valor foi maior do que os meses do outro periodo. O mês de setembro de 1997 foi o que apresentou menor desprendimento de $\mathrm{CO}_{2}$ (Figura 7). 


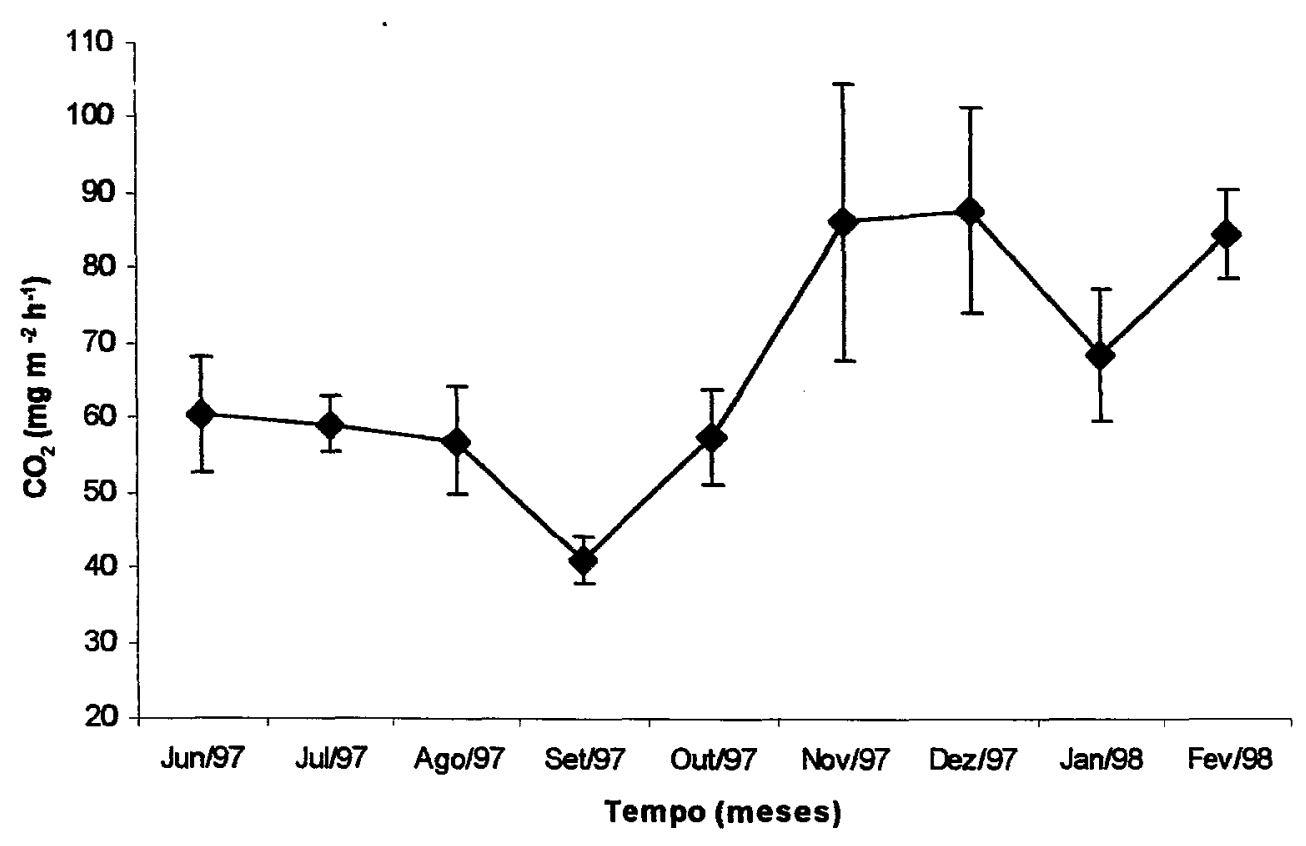

Figura 7 - Média geral de $\mathrm{CO}_{2}$ liberado do solo considerando todos os tratamentos do povoamento de eucalipto ao longo do tempo.

Esse comportamento pode ser atribuído, provavelmente, às altas temperaturas, umidade do solo e precipitação no período de novembro de 1997 a fevereiro de 1998 (Tabelas 1 e 2). Ressalta-se ainda que no período compreendido entre dezembro e março, há uma concentração de $57 \%$ da precipitação anual. No mês de janeiro ocorreu um veranico e aconteceram as menores médias pluviométricas do período (Tabela 1) e de umidade de solo (Tabela 2). Esses dados explicam a queda na respiração durante pleno verão.

Os dados aqui apresentados estão de acordo com Poggiani et al. (1983), que encontraram maiores valores de $\mathrm{CO}_{2}$ liberado no verão e menores valores no inverno. Outros autores como Anderson (1975); Edwards \& Harris (1977); Toland \& Zak (1994); Gonçalves (dados não publicados), Weber (1990) também encontraram maiores médias no verăo, mas as menores médias para o outono, e este último autor, para outono e primavera. 


\subsection{2 - Comparação entre o povoamento de eucalipto e a vegetação natural (cerradão)}

Através da Figura 7, observa-se que em todos os meses, a média da liberação de $\mathrm{CO}_{2}$ na vegetação natural sempre foi maior que aquela no povoamento de eucalipto (TMA). O teste $\mathrm{T}$ confirma tais resultados, mostrando que há diferença significativa ao nível de $5 \%(T=1,81246151, p=0,01012362)$.

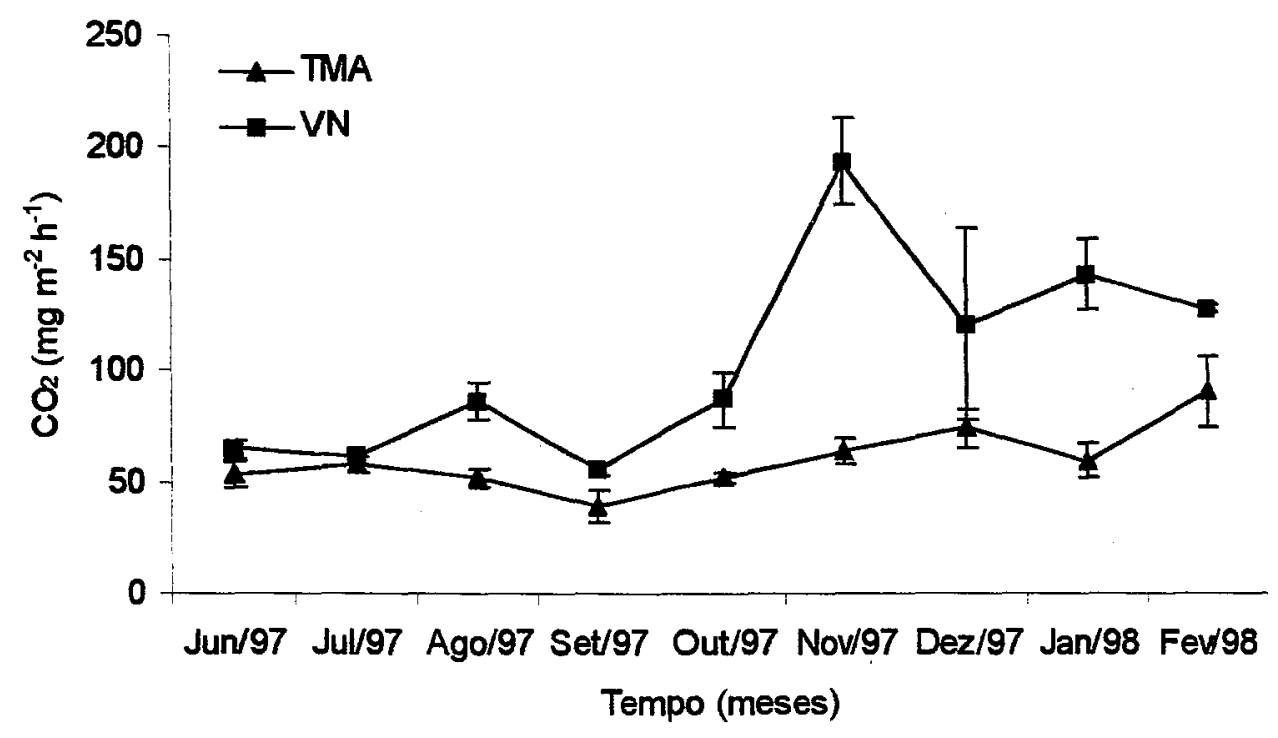

Figura 8 - Médias mensais de emissão de $\mathrm{CO}_{2}$ no tipo de manejo $\mathrm{A}$ (TMA) e na vegetação natural (VN).

Esses resultados são condizentes, pois presume-se que 0 cerradão apresente uma maior diversidade de organismos, bem como interações harmônicas dos mesmos entre si e com o meio, sendo que o povoamento de eucalipto se apresenta bem simplificado quando comparado com o cerradão. 
Outros fatores que contribuiram para maiores valores de $\mathrm{CO}_{2}$ na vegetação natural, foram as temperaturas mais amenas (Tabela 1) e umidade mais alta (Tabela 2) do solo encontrados neste ecossistema. Alguns autores, como Della Bruna (1985), chamam a atenção para a importância da temperatura e umidade no processo de decomposição.

Os valores mostrados estão de acordo com aqueles encontrados por vários autores, como: Martins \& Matthes (1978), Poggiani (1977), Santos \& Grisi (1981), Bowden et al. (1992).

No povoamento de eucalipto, foi observado que havia um acúmulo do material orgânico, não ocorrendo o mesmo na área de vegetação natural, dando indícios de que o processo de decomposição no primeiro ecossistema, é menos intenso que no segundo, haja vista os povoamentos de eucalipto em geral, apresentarem um baixo teor de nutrientes e uma alta relação $\mathrm{C}: \mathrm{N}$, como é ressaltado por Della Bruna et al. (1991). Um outro fator que pode ter contribuído para isso, é menor relação proteína:lignina, ou ainda, segundo Florenzano (1957), devido à presença de substâncias inibidoras do crescimento e da atividade microbiana sobre o material em decomposição. Gama-Rodrigues et al. (1997), também verificaram que em solos sob eucalipto e pinheiro houve um menor potencial de decomposição da matéria orgânica.

Martins \& Matthes (1978), ao fazerem uma comparação de três diferentes ecossistemas na Amazônia (floresta arenícola, campinarana, e campina), através da liberação de $\mathrm{CO}_{2}$ do solo, encontraram uma maior média para a floresta arenícola, sendo que os autores atribuem a isso, às diferenças aparentes de biomassa entre os três tipos de vegetação, ressaltando ainda que floresta arenícola a decomposição é mais rápida.

Geraldes et al. (1995), concluiram que a substituição da mata natural por pastagens, associados a outros parâmetros físico-químicos, reflete na quantidade de biomassa microbiana do solo, sendo que a pastagem conseguiu manter por 4 anos uma microbiota maior que a encontrada na mata 
natural. Após 10 anos, esse nível se aproximou do original, declinando gradativamente nos anos subseqüentes.

Em Marrocos, Pochon et al. (1959), analisando a influência da plantação de Eucalyptus camadulensis e Eucalyptus gomphocephala no solo, ressaltam que as referidas plantaçōes foram desfavoráveis à microbiologia do solo. Outros autores como Fournier (1985) e Castro (1995) também demonstraram que em solos em que há atividade agrícola, as condições químicas, físicas e biológicas são desfavoráveis.

\subsection{Velocidade de infiltração de água no solo}

\subsubsection{Comparação entre os diferentes tipos de manejo}

A análise de variância para a velocidade de infiltração de água no solo sob o povoamento de eucalipto mostrou que houve efeito significativo entre as profundidades $(F=16,696, p<0,001)$. No entanto, não houve efeito significativo entre os tipos de manejo e, nem tão pouco, da interação entre o tipo de manejo e a profundidade, significando que não há dependência entre os dois fatores em estudo.

$\mathrm{Na}$ Figura 9 observa-se que as maiores médias de infiltração básica, para todos os tipos de manejo, foram para a profundidade de $20 \mathrm{~cm}$. Observa-se ainda uma tendência de maiores valores para os tipos de manejo $\mathrm{A}$ e $E$ nas duas profundidades, principalmente na profundidade de $6 \mathrm{~cm}$. Constatou-se uma menor velocidade de infiltração básica a $6 \mathrm{~cm}$ de profundidade para o TMG e TMC. 


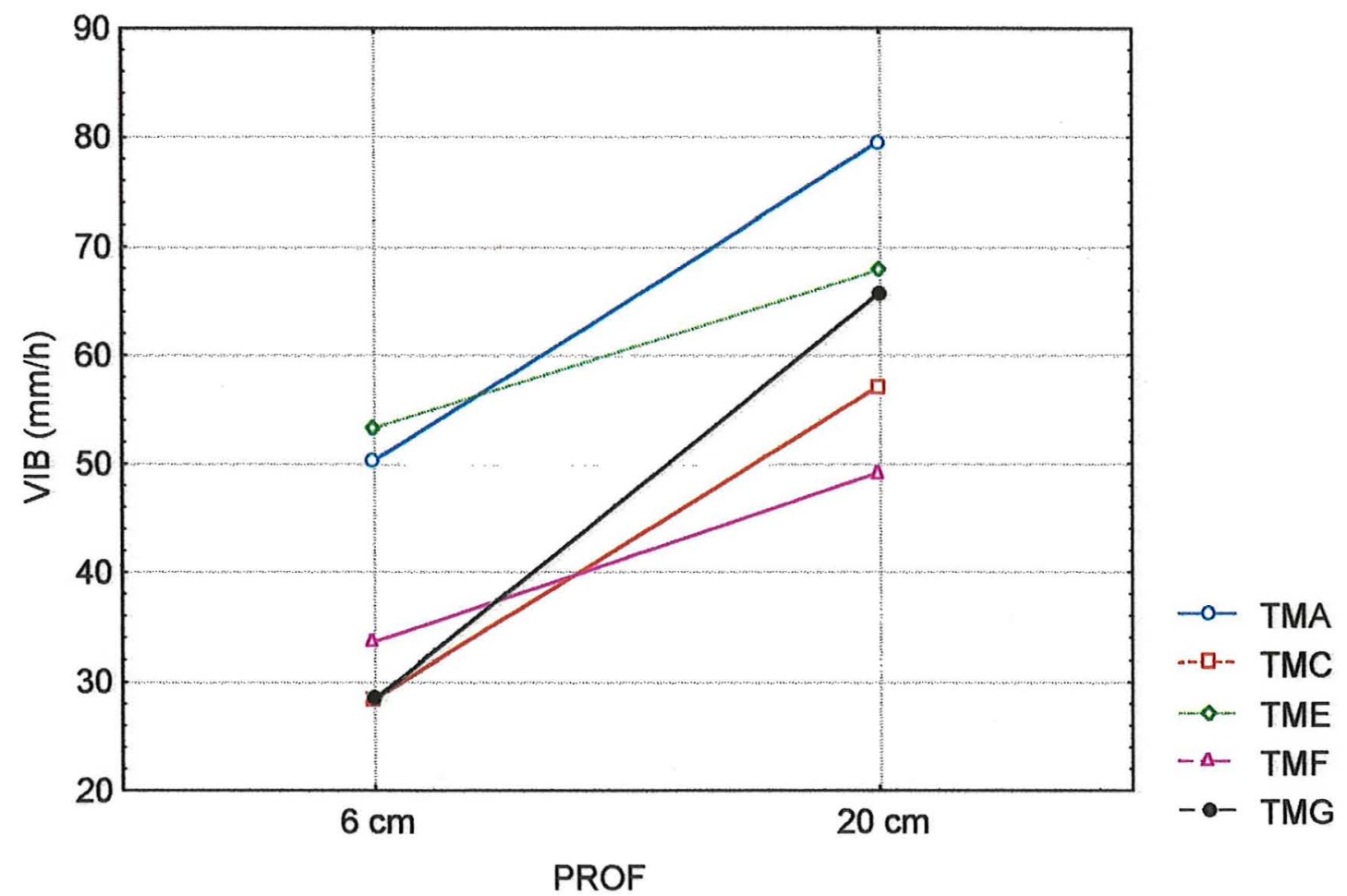

Figura 9 - Velocidade de infiltração básica medida em duas profundidades, durante o mês de setembro de 1997, em solo sob povoamento de Eucalyptus grandis submetido a diferentes tipos de manejo

Nas camadas mais profundas, a velocidade de infiltração é mais constante, pois o solo é mais homogêneo e sofre menor influência do meio externo, inclusive dos tratamentos. Este fato pode ser confirmado através do coeficiente de variação de cada profundidade, que foram de $31,16 \%$ a $6 \mathrm{~cm}$ e $18,07 \%$ a $20 \mathrm{~cm}$. Tanto Arzeno (1990), ao avaliar a infiltração de água utilizando um permeâmetro de campo à profundidades de 15 e $50 \mathrm{~cm}$, como Oliveira (1977) que trabalhou com infiltrômetro de anel, também encontraram altos valores para o CV.

As maiores médias observadas para a profundidade de $20 \mathrm{~cm}$ foram devido a camada superficial ser a mais afetada por práticas de manejo de solo. Qualquer impedimento à entrada de água no perfil acontece na camada 
superficial. Isso leva a inferir que à medida que aumenta a profundidade, há um aumento na velocidade de infiltração de água no solo. Arzeno (1990), também menciona que a camada superior é a que mais limita infiltração de água no solo.

Os tipos de manejo que apresentaram tendência de maior velocidade de infiltração foram o povoamento intacto (TMA) e onde o povoamento foi colhido e os restos culturais removidos (TME). A diferença para esses dois tipos de manejo em relação aos demais, ocorreu, principalmente, na profundidade de $6 \mathrm{~cm}$.

O TMA por se tratar de uma plantação com, aproximadamente 9 anos, apresenta um sistema radicular bem desenvolvido e profundo. Isso contribui para uma maior velocidade de infiltração de água no solo. Essas raízes vão morrendo, contribuindo para o aumento do teor de matéria orgânica e ainda gerando canais que facilitam a descida da água. Porém onde foram retirados todos os restos culturais da superfície do solo (TME), resultando num menor teor de matéria orgânica, esperava-se uma menor velocidade de infiltração de água no solo do que foi observado. Autores como Bertoni \& Pestana (1964), Foglino (1965) e Kiehl (1985), afirmam que a matéria orgânica favorece uma maior velocidade de infiltração de água no solo.

A menor velocidade de infiltração do solo onde houve a queima de todos os resíduos culturais, mesmo sendo um tipo de manejo que apresentou um alto teor de matéria orgânica, pode ser explicado pela influência do fogo. Segundo Primavesi (1990), o fogo afeta a estrutura do solo, alterando suas características granulométricas, desfaz os grumos, tornando-o mais compacto, diminuindo a porosidade e, consequentemente, a velocidade de infiltração de água.

Com relação à áreas queimadas e a velocidade de infiltração de água no solo, Poggiani et al. (1983) e Hester et al. (1997) também verificaram uma redução na velocidade de infiltração de água no solo em áreas em que houve a passagem do fogo. Os primeiros autores constataram uma redução de 
$50 \%$. Já Terren (1993) verificou que não houve diferença significativa entre áreas queimadas e não queimadas quando o fogo é controlado e com pequena intensidade.

Devido ao restos culturais deixados na superfície do solo no TMC (cultivo mínimo) e, consequentemente maior teor de matéria orgânica (Tabela 3 e 4), esperava-se uma maior velocidade de infiltração de água no solo, pois como já foi ressaltado há uma relação direta entre o teor de matéria orgânica $e$ a velocidade de infiltração de água no solo.

\subsubsection{Comparação entre o povoamento de eucalipto e a vegetação natural (cerradão)}

Através da Tabela 5, observou-se que a camada superficial $(6 \mathrm{~cm})$ foi a que apresentou menores valores. Quando foram comparados os tipos de cobertura vegetal, observou-se que o solo sob vegetação natural apresentou a maior velocidade de infiltração de água no solo.

Tabela 5 - Valores médios da infiltração de água em solo sob povoamento de eucalipto e vegetação natural (cerradão)

\begin{tabular}{ccc}
\hline $\begin{array}{c}\text { Cobertura } \\
\text { Vegetal }\end{array}$ & \multicolumn{2}{c}{ Velocidade de infiltração básica $\left(\mathbf{m m ~ \mathbf { ~ } ^ { - 1 } )}\right.$} \\
\cline { 2 - 3 } & $\mathbf{6 ~} \mathbf{~ c m}$ & $\mathbf{2 0} \mathbf{~ c m}$ \\
\hline VN & 64,13 & 106,17 \\
TMA & 50,25 & 79,46 \\
\hline
\end{tabular}

VN: Vegetação Natural (cerradão) e TMA: Tipo de manejo A do povoamento de eucalipto

No cerradão há, provavelmente, um maior teor de matéria orgânica, pois se trata de um ecossistema natural onde a deposição de 
resíduos e a ciclagem de nutrientes vêm acontecendo há muito mais tempo. Isso explica a maior velocidade de infiltração de água no solo nas duas profundidades estudadas. Bertol \& Santos (1995) verificaram que em solos com lavouras anuais em preparo convencional durante 15 anos, houve uma redução na taxa de infiltração de $89 \%$ em relação a mata natural. Anjos et al. (1994) verificaram altos valores para a mata nativa quando comparados a outros sistemas.

Os valores aqui encontrados estão próximos àqueles encontrados por outros autores como; Arzeno (1990), Leite \& Medina (1984).

\subsection{Mesofauna do Solo}

No geral foram observados 12 grupos faunísticos nas áreas estudadas. Ocorreram 8 grupos, tanto no povoamento de eucalipto, como no cerradão (Tabela 6). Um dos grupos é constituído por insetos não identificados, o que aumenta a possibilidade de existir maior diversidade. 
Tabela 6 - Número de indivíduos pertencentes aos diferentes grupos faunísticos presentes nos ambientes estudados

\begin{tabular}{|c|c|c|c|c|c|}
\hline \multirow{3}{*}{$\begin{array}{l}\text { Grupos } \\
\text { faunísticos }\end{array}$} & \multicolumn{4}{|c|}{ Povoamento de eucalipto } & \multirow{3}{*}{$\begin{array}{c}\text { Vegetação } \\
\text { natural }\end{array}$} \\
\hline & TMA & TMC & TME & TMG & \\
\hline & & \multicolumn{3}{|c|}{ indivíduos $\mathrm{m}^{-2}$ de solo } & \\
\hline Ácaros & 909 & 2159 & 341 & 152 & 6136 \\
\hline Colêmbolos & 189 & 0 & 114 & 114 & 303 \\
\hline Homópteros & 76 & 38 & 76 & 0 & 0 \\
\hline Dipteros & 38 & 152 & 76 & 38 & 0 \\
\hline Sinfilos & 38 & 0 & 38 & 0 & 0 \\
\hline Cigarrinhas & 38 & 0 & 0 & 0 & 0 \\
\hline Trips & 0 & 0 & 38 & 38 & 38 \\
\hline Strepsipteros & 0 & 0 & 38 & 0 & 38 \\
\hline Coleópteros & 0 & 0 & 0 & 0 & 189 \\
\hline Pseudoescorpiōes & 0 & 0 & 0 & 0 & 114 \\
\hline Insetos (ñ idents.) & 0 & 0 & 0 & 0 & 265 \\
\hline Formigas & 0 & 0 & 0 & 0 & 152 \\
\hline
\end{tabular}

TMA: povoamento intacto; TMC: cultivo mínimo; TME: retirada dos residuos; TMG: queima dos residuos

$\mathrm{Na}$ vegetação natural não foram encontrados indivíduos dos grupos homópteros, dípteros, sínfilos e cigarrinhas. Todavia os grupos de coleópteros, pseudoescorpião, insetos não identificado e formiga, só ocorreram neste ecossistema. Isso mostra que há uma certa especificidade dos organismos que ocorrem em solos sob ecossistemas distintos.

\subsubsection{Comparação entre o os diferentes tipos de manejo}

Através do teste $\chi^{2}$ (Qui-Quadrado), obteve-se o valor para $\chi^{2}$ observado $=1093$ e $\chi^{2}$ tabelado $(1 \%)=16,81$, indicando desta forma, que há 
evidências ao nível de $1 \%$ de probabilidade, de que a densidade de indivíduos depende do tipo de manejo no povoamento de eucalipto (Tabela 7).

Tabela 7 - Valores observados de grupos de animais que representam a mesofauna edáfica, de um solo sob povoamento de Eucalyptus grandis submetido a diferentes tipos de manejo

\begin{tabular}{lcccc}
\hline \multicolumn{1}{c}{$\begin{array}{c}\text { Grupos de } \\
\text { Animais }\end{array}$} & TMA & TMC & TME & TMG \\
\cline { 2 - 5 } & & individuos $\mathbf{~ m}^{-2}$ & de solo & \\
\cline { 4 - 5 } Ácaros & 909 & 2159 & 341 & 152 \\
Colêmbolos & 189 & 0 & 114 & 114 \\
Outros & 189 & 189 & 265 & 152 \\
\hline Total & $\mathbf{1 2 8 7}$ & $\mathbf{2 3 4 8}$ & $\mathbf{7 2 0}$ & $\mathbf{4 1 8}$ \\
\hline
\end{tabular}

TMA: povoamento intacto; TMC: cultivo mínimo; TME: retirada dos residuos; TMG: queima dos resíduos

Verifica-se que, no total, os tipos de manejo A e C apresentaram os maiores valores de indivíduos por $\mathrm{m}^{2}$ de solo e os tipos de manejo $\mathrm{E}$ e o $\mathrm{G}$ apresentaram os menores valores.

Esses resultados ocorreram, porque nos dois primeiros tipos de manejo há presença dos resíduos culturais na superfície do solo que além de servir como alimento para os organismos, ainda reduz as perdas de água do solo por evaporação, possibilitando uma maior umidade do mesmo. Santos et al. (1994), verificaram que os fatores umidade do solo e maior quantidade de matéria orgânica favorecem o aumento da população de ácaros e colêmbolos.

Teixeira \& Schubart (1988) e Oliveira \& Franklin (1993), verificaram que a queima da biomassa vegetal da floresta provoca a morte de grande quantidade de animais, reduzindo a diversidade faunística do solo. No entanto, Damé et al. (1996), concluíram que uma ou duas queimas com fogo de 
baixa intensidade em pequenas áreas e em mosaico, não afetam a população de colêmbolos e ácaros do solo.

Ainda na Tabela 7, verifica-se que predominaram os ácaros e que não houve presença de colêmbolos

A não detecção de colêmbolos no TMC pode ser explicado devido aos artrópodes se apresentarem de forma agregada. Como foram coletadas apenas 3 amostras em cada parcela do bloco, a amostragem não foi representativa para esse grupo de animais do solo. Um outro fator que pode ter contribuído para a não detecção desse grupo, é que duas lâmpadas sobre as três amostras do TMC apresentaram defeito durante a noite do período de extração.

Em todos os tipos de manejo do povoamento de eucalipto, o grupo dos ácaros predominou sobre os outros grupos detectados (TMA =70\%; TMC = $92 \% ; \mathrm{TME}=47 \%$; $\mathrm{TMG}=37 \%$ ).

\subsubsection{Comparação entre o povoamento de eucalipto e a vegetação natural (cerradão)}

Através do teste $\chi^{2}$ (Qui-Quadrado), obteve-se $\chi^{2}$ observado $=249$ e $\chi^{2}$ tabelado $(1 \%)=9,21$, indicando desta forma, que há evidências ao nível de $1 \%$ de probabilidade, de que os valores de indivíduos dependem do tipo de vegetação (Tabela 8 ). 
Tabela 8 - Valores observados de grupos de animais que representam a mesofauna edáfica de um solo sob povoamento de eucalipto (TMA) e vegetação natural (cerradão).

\begin{tabular}{lcc}
\hline \multicolumn{1}{c}{$\begin{array}{c}\text { Grupos de } \\
\text { Animais }\end{array}$} & \multicolumn{2}{c}{ Tipos de Vegetação } \\
& TMA & VN \\
\cline { 2 - 3 } Ácaros & 909 & individuos $\mathbf{~ m}^{-2}$ de solo \\
Colêmbolos & 189 & 6136 \\
Outros & 189 & 303 \\
\hline Total & $\mathbf{1 2 8 7}$ & 795 \\
\hline
\end{tabular}

TMA: povoamento intacto; e VN: vegetação natural (cerradão)

Observou-se que para todos os grupos faunísticos, a vegetação natural (Cerradão) apresentou maiores valores. Isso, provavelmente, ocorreu, devido aos ecossistemas naturais apresentarem uma maior diversidade em espécies vegetais e, geralmente, maior teor de matéria orgânica, promovendo um "microambiente" favorável à atividade destes organismos. Isso leva a inferir que a retirada da vegetação natural para a implantação de monocultivos de eucalipto, proporciona uma diminuição na diversidade da fauna do solo. Melo (1984) afirma que a transformação de floresta primária em áreas cultivadas causa efeito quantitativo e qualitativo sobre a fauna do solo. Segundo Guerra et al. (1982), em áreas cobertas por vegetação natural, realmente, há uma maior diversidade de organismos do que em áreas antropizadas.

Como já foi enfatizado anteriormente, a vegetação natural (cerradão) apresenta uma maior complexidade, uma maior diversidade de espécies vegetais e ainda um dossel vegetal que impede não só a entrada, mas também a saida de energia. Com isso há uma maior umidade do solo. Outro fato que deve ser levado em consideração, é que não foi verificado um acúmulo de serapilheira na superfície do solo, o que já é um indício de que os organismos (mesofauna e microrganismos) ali presentes são muito mais ativos, 
ocasionando uma decomposição acelerada, não havendo tempo de acúmulo de material.

Nos dois ecossistemas estudados, o grupo dos ácaros predominou sobre os outros grupos detectados. Foi observado que o número de ácaros (Tabela 8 ) aumentou quase 7 vezes do eucalipto para a vegetação natural e que o número de colêmbolos apresentou menor incremento.

Isso leva a inferir uma certa tolerância dos colêmbolos, bem como uma sensibilidade dos ácaros às modificações causadas ao meio.

Observa-se que em todos os tipos de manejo estudados no povoamento de eucalipto, bem como na vegetação natural há predominância de ácaros e colêmbolos em relação aos outros grupos de organismos do solo (Tabelas 7 e 8). Estes dados são confirmados por Guerra et al. (1982), Sautter \& Trevisan (1994), Teixeira \& Schubart (1988), Melo (1984), Sautter \& Santos (1994), Damé et al. (1996). 


\section{CONCLUSÕES E CONSIDERAÇÕES FINAIS}

A prática de cultivo mínimo promoveu um aumento no teor de matéria orgânica do solo. Os resíduos culturais mantidos na superfície do solo, tanto no cultivo mínimo quanto no povoamento intacto, foram de suma importância na redução da variação da temperatura e na conservação da umidade do solo.

A queima dos resíduos culturais da superfície do solo sob eucalipto, favoreceu a fertilidade do mesmo liberando maior quantidade de $\mathrm{CO}_{2}$, no entanto promoveu uma redução na capacidade de infiltração de água na camada superficial do solo e na mesofauna edáfica. Na camada mais profunda a velocidade de infiltração básica é maior do que na camada superficial.

A maior liberação de $\mathrm{CO}_{2}$ da superfície do solo ocorre no período que corresponde ao final da primavera e durante todo o verão.

Em todos os tipos de manejo avaliados no povoamento de eucalipto, bem como no cerradão, houve predominância de ácaros na superfície do solo.

No povoamento de eucalipto, onde houve a prática de cultivo mínimo (TMC) e a manutenção do povoamento intacto (TMA), a população faunistica foi maior.

A vegetação natural (cerradão) apresentou maior liberação de $\mathrm{CO}_{2}$, maior velocidade de infiltração de água no solo e maior densidade e diversidade da mesofauna edáfica, do que o povoamento intacto de eucalipto.

As observaçōes efetuadas ao longo desta pesquisa, mostraram-se úteis para avaliar as condiçōes edáficas de povoamentos florestais implantados. 
Os resultados obtidos podem servir como indicadores das características ecológicas do solo sob diferentes tipos de manejo e em relação à vegetação natural. Ao comparar um sistema de monocultura (povoamento de eucalipto) com um ecossistema natural (cerradão), presume-se que o sistema de monocultura será ecologicamente mais equilibrado, quanto mais se aproximar às características edáficas do ecossistema natural.

Considerando que as observações foram efetuadas, durante a fase inicial do crescimento do eucalipto após a reforma, faz-se necessário dar continuidade aos estudos na área, a fim de serem verificados os efeitos a longo prazo. Particular atenção deve ser dada às conseqüências da queima, que é uma das maneiras mais práticas e baratas de limpeza de área, mas que a longo prazo, pode causar danos ao solo, comprometendo a produtividade dos ecossistemas. 
ANEXOS 
Anexo A Análise da variância ${ }^{1}$ e teste $\mathrm{F}$ para $\circ \mathrm{CO}_{2}$ liberado do solo sob eucalipto (dados transformados $\Rightarrow x=1 / y$ )

\begin{tabular}{|c|c|c|}
\hline Causas de Variação & GL & $\overline{\text { QN }}$ \\
\hline $\begin{array}{l}\text { Blocos (B) } \\
\text { Tipo de Manejo (T) } \\
\text { Resíduo (A) }\end{array}$ & $\begin{array}{r}3 \\
4 \\
12\end{array}$ & $\begin{array}{l}0,0000027 \\
0,0000234 \text { * } \\
0,0000069\end{array}$ \\
\hline Parcela & 19 & \\
\hline $\begin{array}{l}\text { Tempo (T') } \\
\text { Interação TxT } \\
\text { Resíduo (B) }\end{array}$ & $\begin{array}{r}8 \\
32 \\
120\end{array}$ & $\begin{array}{l}0,0003340^{\text {}} \\
0,0000109^{n s} \\
0,0000080\end{array}$ \\
\hline Total & 179 & \\
\hline C.V (A) & & $5,374 \%$ \\
\hline C.V (B) & & $17,356 \%$ \\
\hline
\end{tabular}

Anexo B Teste $\mathrm{T}$ para as médias originais de $\mathrm{CO}_{2}$ entre vegetação natural (cerradão) e o povoamento de eucaliptos

\begin{tabular}{lllll}
\hline Médias estatísticas & VN & & TMA & \\
\hline Média & 104,337917 & a & 59,9968958 & b \\
Variância & 2106,06535 & & 222,578551 & \\
Observaçōes & 9 & 9 & \\
\hline GL & 16 & & &
\end{tabular}

VN: Vegetação natural e TMA: Tipo de manejo A do povoamento de eucalipto

Médias seguidas de letras iguais na linha, não diferem significativamente entre si ao nivel de $5 \%$

Anexo $C$ Análise de variância e teste $F$ para a velocidade de infiltração básica no povoamento de eucalipto (dados transformados $=>x=\ln (Y)$ )

\begin{tabular}{lrl}
\hline Causas de Variação & GL & QM \\
\hline Blocos & 3 & \\
Tipo de Manejo (A) & 4 & $0,304900^{\text {ns }}$ \\
Profundidade (B) & 1 & $2,987352^{* *}$ \\
A x B & 4 & $0,083997^{\text {ns }}$ \\
Residuo (B) & 27 & 0,272595 \\
\hline \multicolumn{1}{c}{ Total } & 39 & \\
\hline
\end{tabular}

** = Significativo pelo teste $F$, ao nivel de 5\%

ns = Não significativo pelo teste $F$

\footnotetext{
${ }^{1}$ Serão apresentados na tabela de ANOVA apenas os GL e os QM, já que as SQ relativos podem ser abtidos pela multiplicação dos GLXQM e o valor do teste F calculado pelas divisões do QM do tipo de manejo/ Qm resíduo (A), $\mathrm{QM}$ tempo/ QM resíduo (B) e QM tipo de manejo $\mathrm{x}$ tempo/QM resíduo (B).
} 
Anexo D Teste $\chi^{2}$ para a mesofauna edáfica do povoamento de eucaliptos sob diferentes práticas de manejo

$\begin{array}{lccccc} & \text { TMA } & \text { TMC } & \text { TME } & \text { TMG } & \\ \text { Ácaros } & 909 & 2159 & 341 & 152 & \mathbf{3 5 6 1} \\ \text { Colêmbolos } & 189 & 0 & 114 & 114 & \mathbf{4 1 7} \\ \text { Outros } & 189 & 189 & 265 & 152 & \mathbf{7 9 5} \\ \text { Total } & 1288 & 2348 & 720 & 417 & \mathbf{4 7 7 3}\end{array}$

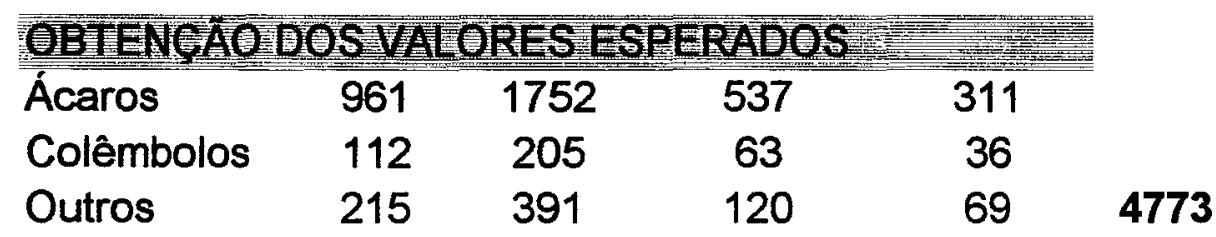

\begin{tabular}{lcccc}
\hline AUADRO AUXILIAR: & & & \\
\hline Ácaros & 2,7825 & 94,568 & 71,554512 & 81,67189 \\
Colêmbolos & 52,679 & 205,03 & 41,082266 & 164,0952 \\
Outros & 2,9714 & 104,27 & 175,7704 & 97,00232 \\
& & & & \\
qui obs & 1093,5 & & \\
qui tab(5\%) & 12,592 & REJEITO \\
qui tab(1\%) & 16,812 & REJEITO &
\end{tabular}


Anexo $\mathrm{E}$ Teste $\chi^{2}$ para a mesofauna edáfica do povoamento de eucaliptos (TMA) e vegetação natural (cerradão)

\begin{tabular}{lrrr} 
& TMA & \multicolumn{1}{c}{ VN } & \\
Ácaros & 909,1 & 6136,4 & $\mathbf{7 0 4 5}$ \\
Colêmbolos & 189,4 & 303,0 & $\mathbf{4 9 2 , 4}$ \\
Outros & 189,4 & 795,5 & $\mathbf{9 8 4 , 8}$ \\
Total & 1287,9 & 7234,8 & $\mathbf{8 5 2 3}$
\end{tabular}

\begin{tabular}{lccc}
\hline OBIENOAODOS VALORES ESPERADOS & ETE \\
\hline Ácaros & 1065 & 5981 & \\
Colêmbolos & 74 & 418 & \\
Outros & 149 & $836 \quad \mathbf{8 5 2 3}$
\end{tabular}

\begin{tabular}{lrl}
\hline QUADROAUIARE & \\
\hline Ácaros & 22,728 & 4,0457474 \\
Colêmbolos & 177,68 & 31,628547 \\
Outros & 11,06 & 1,9687664 \\
& & \\
qui obs & 249,11 \\
qui tab(5\%) & 5,9915 REJEITO \\
qui tab(1\%) & 9,2104 REJEITO
\end{tabular}




\section{REFERÊNCIAS BIBLIOGRÁFICAS}

ADAMOLI, J.; MACEDO, J.; AZEVEDO, L.G.; MADEIRA NETO, J. Caracterização da região dos Cerrados. In: GOEDERT, W. J. (Ed.) Solos dos Cerrados: tecnologia e estratégia de manejo. São Paulo: Nobel, 1986. p.33 -74 .

AGUIAR, J. V. Parâmetros físico-hídricos de um solo sem cobertura vegetal e avaliação do "modelo de umidade do solo para atividades agrícolas" (MUSAG). Piracicaba, 1997. 76p. Tese (Doutorado) - Escola Superior de Agricultura "Luiz de Queiroz", Universidade de São Paulo.

ALVES, M. I. F.; MACHADO, A. A.; ZONTA, E.P. Tópicos especiais de estatística experimental utilizando o SANEST (Sistema de análise estatística para microcomputadores). In: SIMPÓSIO DE ESTATÍSTICA APLICADA À EXPERIMENTAÇÃO AGRONÔMICA, 5.; REUNIÃO ANUAL DA SOCIEDADE INTERNACIONAL DE BIOMETRIA, 38;; Porto Alegre, 1993: Resumos. Porto Alegre: Universidade Federal do Rio Grande do Sul,.110p.

ALVIM, P. T. Teoria sobre a formação dos campos cerrados. Revista Brasileira de Geografia, v.16, n.4, p. 496 - 498, 1954. 
ANDERSON, J. M. Succession, diversity and trophic relationships of some soil animals in decomposing leaf litter. Joumal of Animal Ecology, v.44, p. 475-495, 1975.

ANJOS, J. T.; UBERTI, A. A. A.; VIZZOTTO, V. J.; LEITE, G. B.; KRIEGER, M. Propriedades físicas em solos sob diferentes sistemas de uso e manejo. Revista Brasileira de Ciência do Solo, v.18, p.139-145, 1994.

ARZENO, J. L. Avaliação física de diferentes manejos de solo em um latossolo roxo - distrófico. Piracicaba, 1990. 259p. Tese (Doutorado) - Escola Superior de Agricultura "Luiz de Queiroz", Universidade de São Paulo.

BALLONI, E. A. O uso intensivo de florestas e seus reflexos na fertilidade do solo. Boletim Técnico SIF, v.2, n. especial, p.83-93, 1979.

BAPTISTA, A. S.; KURTZ, C.; REIS, E.F.; MASSARIOL, J.M. KONFLONS, V.; BERTOL, I. Avaliação das propriedades de uma terra bruna estruturada e um cambissolo húmico submetidos à semeadura direta. In: SEMINÁRIO CATARINENSE DE INICIAÇÃO CIENTÍFICA, 4, Larges, 1996. Resumos. Larges: Universidade Federal de Santa Catarina, 1994. p.727.

BAVER, L. D.; GARDNER, W. H.; GARDNER, W.R. Física del suelos (Soil Physics). México: Union Tipográfica Editorial Hispanoamerica, 1973. 529p.

BERTOL, I.; SANTOS, J.C.P. Uso do solo e propriedades físico-hídricos no planalto Catarinense. Pesquisa Agropecuária Brasileira, v.30, n.2, p. 263-267, 1995. 
BERTONI, J. Determinação da velocidade de infiltração de água no solo, por meio de diagramas de pluviógrafos e limnígrafos. Bragantia, v.18, n.13, p. $170-197,1959$.

BERTONI, J.; PESTANA, F. I. Relação chuva/perdas por erosão em diferentes tipos de solo. Bragantia, v. 23, p.3-11, 1964.

BOWDEN, R. D.; NADELHOFFER, K. J.; BOONER, R. D.; MELILLO, J. M.; GARRISON, J. B. Contribuitions of aboveground litter, bellowground litter, and root respiration to total soil respiration in a temperature mixed hardwood forest. Canadian Journal of Forest Research, v.23, p.14021407, 1992.

BRADY, N. C. Natureza e propriedades dos solos. 7.ed. Rio de Janeiro: Freitas Bastos, 1989. 878p.

BRAGAGNOLO, N.; MIELNICZUK, J. Cobertura do solo por resíduos de oito seqüências de cultura e seu relacionamento com a temperatura e umidade do solo, germinação e crescimento inicial do milho. Revista Brasileira de Ciência do Solo, v.14, p.91-98, 1990.

BRASIL. Ministério da Agricultura. Secretaria Nacional de Produção. Secretaria de Recursos Naturais. Coordenadoria de Conservação do Solo e Água. Manejo e conservação do solo: informações técnicas. Brasília: s. ed., 1983. $65 p$. 
CALLE, J. M. L.; VELLASCO, F. Microbial population and humus types in semiarid soils. Anales de Edafologia Agrobiologia. v.30, n.3/4, p.285-292, 1977.

CARDOSO, E.J.B.N. Ecologia microbiana do solo. In: CARDOSO, E.J.B.N.; TSAI, S.M.; NEVES, M.C.P. (Coord.) Microbiologia do solo. Campinas: SBCS, 1992. cap.3, p.33 - 39 .

CASTRO, L. Efecto del uso agrícola y el barbecho sobre los contenidos de biomassa microbiana de Utisoles y Andisoles de Costa Rica. Agronomía Costarricense, v.19, n.2, p.59-65. 1995.

COUTINHO, L. M. O cerrado e a ecologia do fogo. Ciência Hoje, v.12, n.68, p.23-30. 1990.

DAMÉ, P. R. V.; QUADROS, F. L. F.; KERSTING, C. E. B.; TRINDADE, J. P. P.; ANTONIOLLI, Z. I. Efeitos da queima seguida de pastejo ou deferimento sobre o residuo, temperatura do solo e mesofauna de uma pastagem natural. Ciência Rural, v.26, n.3, p.391-396, 1996.

DELLA BRUNA, E. A serapilheira de eucalipto: efeitos de componentes antibacterianos e de nutrientes na decomposição. Viçosa, 1985. 54p. Dissertação (M. S) - Universidade Federal de Viçosa. 
DELLA BRUNA, E.; BORGES, A. C.; FERNANDES, B.; BARROS, N. F.; MUCHOVEJ, R. M. C. Atividade da microbiota de solos adicionados de serapilheira de eucalipto e de nutrientes. Revista Brasileira de Ciência do Solo, v.15, p.15-20, 1991.

DELLA BRUNA, E.; FERNANDES, B.; BORGES, A. C.; FILLHO, J. A.; BARROS, N. F. Efeito do extrato de serapilheira de Eucalyptus sobre o crescimento microbiano. Pesquisa Agropecuária Brasileira, v.24, n.12, p.1523-1528, 1989.

DEMATTÊ, J. L. I.; DEMATTÊ, J. A. M. Comparações entre as propriedades químicas de solo das regiões da floresta Amazônica e do Cerrado do Brasil Central. Scientia Agrícola, v.50, n.2, p. 272-286, 1993.

EDWARDS, N. T.; HARRIS, W. F. Carbon cycling in a mixed deciduous forest floor. Ecology, v.58, p.431-437, 1977.

EMBRAPA - Empresa Brasileira de Pesquisa Agropecuária. Manual de Métodos de Análise de Solo. Rio de Janeiro: Rio de Janeiro, 1997. 212p.

EMBRAPA - Empresa Brasileira de Pesquisa Agropecuária. Relatório Elaborado pelo Grupo de Trabalho instituido pela Resolução no. R.D. 040/74. Brasília, 1975 
FERNANDES, L. A.; SIQUEIRA, J. O.; GUEDES, G. A. A.; CURI, N. Propriedades quimicas e bioquímicas de solo sob vegetação de mata e campo cerrado adjacentes. Ciência e Agrotecnologia, v.21, n.1, p.58-70, 1997.

FERRI, M. G. Sobre a origem, a manutenção e a transformação dos cerrados, tipos de savana do Brasil. Revista de Biologia, v.9, n.1/4, p.1-3, 1973.

FITKAU, E. J.; KLINGE, $H$. On biomass and trophic struture of the central Amazonian rain forest ecossystem. Biotropica, v. 5, n.10, p. 2-14, 1973.

FLECHTMANN, C. H. W. Elementos de acarologia. São Paulo: Nobel, 1975. $344 p$.

FLORENZANO, C. Ricerche sui terreni coltivati ad eucalitto (II - Ricerche microbiologiche e bioquimiche). Publ. Centro Sper. Agríc. For., v.1, p. 131$152,1957$.

FOGLINO, E. La lotta antierosiva en Ecuador. Revista Agropecuária Subtropical Tropical, v.59, p.10-12, 1965.

FONSECA, S.; BARROS, N. F.; NOVAIS, R. F. et al. Alterações de um latossolo sob eucalipto, mata natural e pastagem. I. Propriedades físicas e químicas. Revista Árvore, v.17, p. 271-288, 1993. 
FOURNIER, L. A. El sector forestal de Costa Rica: Antecedentes y perspectivas. Agronomía Costarricense, v.9, n.2, p. 253-260, 1985.

GAMA-RODRIGUES, E. F.; GAMA-RODRIGUES, A. C.; BARROS, N. F. Biomassa microbiana de carbono e de nitrogênio de solos sob diferentes coberturas florestais. Revista Brasileira de Ciência do Solo, v. 21, p. 361$365,1997$.

GERALDES, A . P. A; CERRI, C. C.; FEIGL, B. J. Biomassa microbiana de solo sob pastagem na Amazônia. Revista Brasileira de Ciência do Solo, v.19, p.55-60, 1995.

GOEDERT, W. J. Região dos Cerrados: potencial agrícola e política para seu desenvolvimento. Pesquisa Agropecuária Brasileira, v.24, n.1, p.1-17, 1989.

GONÇALVES, J. L. M. SEMINÁRIO SOBRE CULTIVO MÍNIMO DO SOLO EM FLORESTAS, 1, Curitiba, 1995. Anais. Piracicaba, CNPFloresta/ IPEF/ UNESPI SIF/ FUPEF, 1995. 162p.

GONÇALVES, J. L. M. Total $\mathrm{CO}_{2}$ output from surface soil and its relationship with soil $\mathbf{N}$ history, substrate temperature and moisture content. s. n. t., $16 p$. 
GRAÇA, P. M. L. A Conteúdo de carbono na biomassa florestal da Amazônia e alteraçōes após queima. Piracicaba, 1997. 105p. Dissertação (M. S) Escola Superior de Agricultura "Luiz de Queiroz", Universidade de São Paulo.

GUERRA, R. T.; BUENO, C. R.; SCHUBART, H. O. Avaliação preliminar sobre os efeitos da aplicação do herbicida Paraquat e aração convencional na mesofauna do solo na região de Manaus - AM. Acta Amazônica, v.12, n.1, p.7-13, 1982.

HAAG, H. P.; ROCHA FILHO, J. V. de C.; OLIVEIRA, G. D. Ciclagem de nutrientes em florestas implantadas de Eucalyptus e Pinus II. Contribuição das espécies de nutrientes na manta. O Solo, v.70, p.28-31, 1978.

HESTER, J. W.; THUROW, T. L..; TAYLOR Jr., C. A. Hidrologic characteristics of vegetation types as affected by prescribed burning. Journal of Range Management, v.50, p.199-204, 1997.

HILLEL, D. Applications of soil physics. New York: Academic Press, 1980. $385 p$.

HILLEL, D. Solo e água: fenômenos e princípios físicos. Porto Alegre: Departamento de Solos/UFRGS, 1970. 231 p.

HUECK, K. A primitividade dos "campos-cerrados" brasileiros e novas observações em seu limite meridional. Boletim Geográfico, v.31, v.230, p.1-126, 1972. 
KIEHL, E. J. Fertilizantes orgânicos. Piracicaba: Agronômica Ceres. 1985. $482 p$.

LEITE, J. A.; MEDINA, B.F. Efeito dos sistemas de manejo sobre as propriedades físicas de um latossolo amarelo do Amazonas. Pesquisa Agropecuária Brasileira, v.19, n.11, p.1417-1422, 1984

LIMA, V. C.; LIMA, J. M. J.; EDUARDO, B. J. F. P.; CERRI, C. C. Biomassa microbiana e conteúdo de carbono do solo em agroecossistemas: comparação entre métodos de preparo de solo. In: SIMPÓSIO BRASILEIRO SOBRE MICROBIOLOGIA DO SOLO, 2.; Resumos. São Paulo, 1992. p. 53.

LOPES, A. S. Solos sob "Cerrado": características, propriedades e manejo. Piracicaba: Instituto da Potassa \& Fosfato: Instituto Internacional da Potassa, 1983. 162p.

LUFF, M. L; HUTSON, B.R. Soil fauna populations. In: HACKETT, B. (Ed.) Land reclamation pratice. Guildford: IPC Business Press, 1977.

MARTINS, F.R.; MATTHES, L.A.F. Respiração edáfica e nutrientes na Amazônia (Região de Manaus): floresta arenícola, campinarana e campina. Acta Amazônica, v.8, n.2, p.233-244, 1978. 
MELO, L. A. S. Impacto do Manejo de agroecossistemas sobre a mesofauna do solo, em áreas de terra firme, na região de Manaus, AM. Manaus, 1984. 117p. Dissertação (M. S) - Instituto Nacional de Pesquisa da Amazônia/Fundação Universidade do Amazonas.

MOURA, V. P. G.; SILVA, M. A.; SANTIAGO, J.; CASTRO, A. J. R. Comportamento e resistência de procedências de Eucalyptus grandis Hill Ex. Maiden à formação de veios de "kino" em Planaltina, DF, área de cerrado. Boletim de Pesquisa Florestal, n.24/25, p.19-35, 1992.

MUNEVAR, F.; WOLLUM, A. G. Efectos of the addition of phosphorus and inorganic nitrogen on carbon and nitrogen mineralization in Andepts from Colombia. Soil Science Society of America Journal, v.41, p.540-545, 1977.

MUSGRAVE, G. W.; HOLTAN, H. N. Infiltration. In: W. T. CHOW. Handbook of applied hydrology, New York: McGraw-Hill Book, 1964. p.121-130.

OLIVEIRA, E. P.; FRANKLIN, E. Efeito do fogo sobre a mesofauna do solo: recomendações em áreas queimadas. Pesquisa Agropecuária Brasileira, v.28, n.3, p.357-369, 1993.

OLIVEIRA, S. L. Efeitos da carga hidráulica, da profundidade de instalação do cilindro interno e do diâmetro do cilindro externo, na determinação da velocidade de infiltração básica (VIB), pelo infiltrômetro de anel. Viçosa, 1977. 32p. Dissertação (M. S) - Universidade Federal de Viçosa. 
PAAR, J. F.; BERTRAND, A. R. Water infiltration into soil. Agronomy, v.12, p.311-342, 1960.

PACífICO HOMEM, V. A cultura do eucalipto no melhoramento do solo. In: CONFERENCIA MUNDIAL DE EUCALIPTO, 2.,Irmãos D. Giorgio e Cia., v.2, p.911-918, 1961.

POCHON, J.; BARJAC, H.; FAIVRE-AMIOT L' influence de plantation d' Eucalyptus au Maroc sur la microflore et l' humus du sol. Ann. Institute Pasteur, v.97, n.3, 1959.

POGGIANI, F.; LIMA, W. de P.; BALLONI, E. A. \& NICOLELLO, N. Respiração edáfica em plantações de coníferas e folhosas exóticas em área de cerrado do estado de São Paulo. IPEF, v.14, p.129-148, 1977.

POGGIANI, F.; REZENDE, G.C.; SUITER FILHO, W. Efeitos do fogo na brotação e crescimento de Eucalyptus grandis após o corte raso e alterações nas propriedades do solo. IPEF, v.24, p.33-41, 1983.

POGGIANI,, F.; OLIVEIRA, R. E.; CUNHA, G. C. Práticas de Ecologia Florestal. Documentos Florestais. Piracicaba. v.16, p.30-36. 1996. 
PRIMAVESI, A. O manejo ecológico do solo: agricultura em regiões tropicais. São Paulo: Nobel, 1990. 549p.

PRIOR, L. O. Biology of Eucalyptus. Studies in Biology. Lodon: Edward Arnold. 82p.

RAIJ, B. van.; QUAGGIO, J. A.; CANTARELLA, H.; FERREIRA, M. E.; LOPES, A. S.; BATAGLIA, O. C. Análise química de solo para fins de fertilidade. Campinas: Fundação Cargill, 1987. 170p.

REICHARDT, K. Dinâmica da matéria e da energia em ecossistemas. Piracicaba: ESALQ/USP, 1996. 505p.

REISSMAN, C. B. Morfologia dos horizontes de húmus em florestas de coniferas do Sul do Brasil. Revista do Setor de Ciências Agrárias, v.5, n.1/2, p.11-16, 1983.

REYNOLDS, W. D.; ELRICK, D. E. A laboratory and numerical assessment of the Guelf Permeameter Method. Soil Science, v.144, n.4, p. 282-299, 1987.

REYNOLDS, W. D.; VIEIRA, S. R.; TOPP, G. C. An assessment of the singlehead analysis for the constant head well permeameter. Canadian Journal of Soil Science, v.72, p.489-501, 1992. 
ROCHA FILHO, J. V. de C.; HAAG, H. P.; OLIVEIRA, G. D.; PITELLI, R. A. Ciclagem de nutrientes em florestas implantadas de Eucalyptus e Pinus I. Distribuição no solo e na manta. Anais da ESALQ, v. 35, p. 113-123, 1978.

SALTON, J. C.; MIELNICZUK, J. Relação entre sistemas de preparo do solo, temperatura e umidade de um podizólico vermelho-escuro de Eudorado do Sul (RS). Revista Brasileira de Ciência do Solo, v.19, p.313-319, 1995.

SAMPAIO, E. V. S. B.; SALCEDO, I. H. Efeito da adição de nitrogênio e palha - $\left({ }^{14} \mathrm{C}\right)$ na liberação de $\mathrm{CO}_{2}$ e formação de biomassa microbiana em latossolo vermelho amarelo. Revista Brasileira de Ciência do Solo, v.6, p. $177-181,1982$.

SANSIGOLO, C. A.; SILVA, H. D.; PEREIRA, R. S.; ALVES, S. T. Nutrição mineral de Eucalyptus. In: HAAG, H. P. (Coord.) Nutrição mineral de Eucalyptus, Pinnus, Araucaria e Gmelina no Brasil. Campinas: Fundação Cargil, 1983. p.1-59.

SANTOS, O.M.S.; GRISI, B.M.. Efeito do desmatamento na atividade dos microrganismos do solo de terra firme na Amazônia. Acta Amazônica, v.11, n.1, p.97-102, 1981.

SAUTTER, K. D.; SANTOS, H. R. Avaliação da estrutura da população da mesofauna edáfica, em diferentes regimes de reabilitação de um solo degradado pela mineração de xistos. Agrárias, v.13, n.1/2, p.31-34, 1994. 
SAUTTER, K. D; TANCK, B. C. B; DIONISIO, J. A; SANTOS, H. R. dos. Estudo da população de oribatei (acari: cryptostigmata), collembola (insecta) e oligochaeta, em diferentes ambientes de um solo degradado pela mineração de xisto a céu aberto. Agrárias, v.13, n.1/2, p.171-174. 1994.

SAUTTER, K. D; TREVISAN, E. Estudo da população de oribatei (acari: cryptostigmata), collembola (insecta) em três sítios distintos de acumulação orgânica sob povoamento de Pinus taeda L. Revista do Setor de Ciências Agrárias, v.13, n.1/2, p.167-169. 1994.

SCHILENTER, R.E. \& CLEVE, K. V. Relationships betwen $\mathrm{CO}_{2}$ evolution from soil, substrate temperature, and substrate moisture in four mature forest types in interior Alaska. Canadian Journal of Forest Research, v.15, p.97-106, 1985.

SERRANO, M. I. P. Mineralização, absorção e lixiviação de nitrogênio em povoamento de Eucalyptus grandis sob cultivo mínimo e intensivo do solo. Piracicaba, 1997. 86p. Dissertação (M. S) - Escola Superior de Agricultura "Luiz de Queiroz", Universidade de São Paulo.

SINHA, R. N. Mites of stored grain in western Canada - Ecology and methods of survey. Proceedings of the Entomological Society of Manitoba, v.20, p.19-33, 1964. 
SKAGGS, R. W.; KHAEEL, R. Infiltration. In: INTERNATIONAL SYMPOSIUM OF MODDELLING AGRICULTURAL FOREST AND RANGELANDS HYDROLOGY, Chicago, 1988. St. Josph. Michigan: American Society of Agricultural Engineers, 1988. p.1-9, 1988.

SOLOMON, M. E. Tyroglyphid mites in stored products - Methods for the study of population density. Annals of Applied Biology, v.32, n.1, p.71-75, 1945.

TEIXEIRA, L.B; SCHUBART, R. O. R. Mesofauna do solo em áreas de floresta e pastagem na Amazônia Central. BOLETIM DE PESQUISA EMBRAPA/ CENTRO DE PESQUISA AGROPECUÁRIA DO TRÓPICO ÚMIDO. v.95, p.1-16, 1988.

TERREN, M. Efectos del fuego controlado en la velocidad de infiltracion del agua en suelos forestales: un caso de estudio en la costa norte de California. Investigacion Agraria, v.2, n.2, p.173-184, 1993.

TOLAND, D.E,; ZAK, D.R. Seasonal patterns of soil respiration in intact and clear-cut northern hardwood forests. Canadian Journal of Forest Research, v.34, p.1711-1716, 1994.

WEBER, M.G. Forest soil respiration after cutting and burning in immature aspen ecosystems. Forest Ecology and Management, v.31, p.1-14, 1990.

WITKAMP; OLSON, J. Breakdown of confined and monconfined oak litter. Oikos, v.13, n.11, p.138-147, 1963. 